\title{
A Model of Response Strategies in Strategic Alliances: A PLS
}

Analysis of a Circumplex Structure

\section{Olivier Furrer, Brian Tjemkes and Jörg Henseler}

The few studies investigating partners' response behavior in strategic alliances often fail to provide empirical support for a large proportion of the relationships they hypothesized. This discrepancy between theory and empirical findings could be attributed to a misconceptualization of response strategies as independent from each other. Indeed, response strategies could be better conceptualized as a circumplex structure rather than as discrete responses. Whereas the circumplex structure of response strategies has been empirically established, it has not yet been taken into account when detecting the effects of potential antecedents on response strategies. A model that accounts for the circumplex structure thus should exhibit superior explanatory power by reducing Type II error. PLS path modeling is particularly suited to substantiate the superiority of such a model, however PLS path modeling as implemented in extant software is not equipped to estimate circumplex structures. Therefore, the objective of the present study is twofold. First, we extend PLS path modeling so that it can handle circumplex structures. Second, building on a circumplex structure of response strategies, we develop and test a model of alliance partners' response strategies and key antecedents. The results of a survey of alliance managers corroborate our expectations and demonstrate that non-significant antecedents become significant when accounting for the circumplex structure. This study thus advances PLS path modeling and contributes to a better understanding of managers' complex decision-making processes in strategic alliances.

\section{Introduction}

In recent decades, strategic alliances have become cornerstones of many firms' competitive strategies (Kale and Singh, 2009). These alliances are defined as long-term, non-equity, cooperative arrangements that partners use to achieve objectives they could not otherwise reach (Das and Teng, 2000). 
Strategic alliances are also mixed-motive ventures, in which partners simultaneously cooperate and compete (Kumar and Nti, 2004). Because of this internal rivalry, alliances often tend to result in premature terminations. A high failure rate of between 60 and 70 percent (Hughes and Weiss, 2007) highlights the need for alliance managers to anticipate their partners' behavior (Tjemkes and Furrer, 2010), as this behavior may be destructive to the alliance (Hibbard et al., 2001). Underperformance and unintended dissolution might be avoided if managers are able to respond to early warning signals (Ariño and Doz, 2000). But, despite a vast amount of scholarly work on alliance governance, there has been little research on partners' response behaviors and how they might be predicted.

Prior studies investigating response behavior in strategic alliances have adopted and extended the exit, voice, loyalty and neglect (EVLN) typology (e.g., Geyskens and Steenkamp, 2000; Hibbard et al., 2001; Ping, 1993). These studies conceptualize response strategies as discrete and organize them in a passive-active and constructive-destructive two-dimensional space (Furrer et al., 2012). Some studies started to investigate the effect of antecedents, such as economic and social satisfaction, on each response strategy (e.g., Tjemkes and Furrer, 2010). Although they contribute to a better understanding of response behavior, these studies often fail to provide empirical support for a large proportion of the relationships they hypothesize. Ping (1993) for example reports seven non-significant effects out of 15 hypothesized relationships, and Tjemkes and Furrer (2010) find 14 non-significant effects out of 28 hypothesized relationships. This discrepancy between theory and empirical findings could be attributed to a misconceptualization of response strategies as independent from one another.

Furrer et al. (2012) thus suggest that response strategies should be conceptualized as a circumplex structure rather than discrete responses. Whereas a circumplex structure, akin to a discrete model, builds on a two-dimensional space, it also stipulates the order of response strategies along the circumference of a circle on the basis of their degree of compatibility (Fabrigar et al., 1997). A key property of such a structure is its continuous nature (Schwartz, 2012), which allows for nonmeasured interstitial responses (Hagedoorn et al., 1999). A continuous structure also implies that antecedents might be related to the whole structure, without showing significant effects on any discrete response strategy or any of the two dimensions of the response strategy space. Thus, prior studies conceptualizing response strategies as discrete might have been misled by statistical tests and falsely rejected hypotheses (Brock, 2003). A model that accounts for the circumplex structure of response strategies may exhibit superior explanatory power, by reducing Type II error, but to date such a model has not been empirically validated. Whereas the circumplex structure of response strategies has been established (Furrer et al., 2012), the continuous nature of the circumplex structure has not been taken into account for detecting the effects of potential antecedents on response strategies.

To substantiate this superior explanatory power of a model that accounts for the circumplex structure of response strategies, we consider partial least squares (PLS) path modeling particularly well suited. As a variance-based technique, it aims to maximize the explained variance of the model (Reinartz et al., 2009). Even with a high number of parameters, as required for estimating a circumplex structure, it allows for smaller sample sizes than traditional structural modeling techniques (Chin and Newsted, 1999; Hair et al., 2012). Furthermore, PLS does not rely on distributional assumptions, which becomes relevant in the presence of heavily right-skewed variables, such as some of the response strategies (Cassel et al., 1999). However, PLS path modeling as implemented in extant PLS software is not equipped to estimate circumplex models. In particular, it does not permit modeling the continuous two-dimensional nature of a circumplex structure.

Thus, the objective of the present study is twofold. First, we extend PLS path modeling so that it can handle circumplex structures. We estimate a hierarchical component model and apply deflation (Lohmöller, 1989) to extract two dimensions that span the response strategies in a circumplex structure. We enhance PLS path modeling so that it can control the component rotation during its runtime. Specifically, by arbitrarily fixing the position of one response strategy, we can align the two dimensions of the circumplex structure with the response strategies. In turn, this 
enhancement enables us to express the effects of potential antecedents in polar coordinates, which is necessary to specify the test of the antecedents on the circumplex structure correctly. We also apply bootstrapping in a novel way to determine confidence regions for the effects of antecedent variables. This enhancement of PLS path modeling can help reduce Type II error in assessing the effects of antecedents on circumplex systems of dependent variables.

Second, building on the circumplex structure of response strategies, we develop and test a model of alliance partners' response strategies and key antecedents. To increase the explanatory power of the model and better represent the actual decision-making context of strategic alliances (Hennart, 2006), we present a circumplex structure of seven response strategies (i.e., exit, opportunism, aggressive voice, creative voice, considerate voice, patience, neglect) and identify antecedents of these response strategies at three different levels of analysis: individual, alliance and environment. That is, we hypothesize direct effects of individual, alliance and environmental factors, and a moderating effect of environmental factors on the circumplex structure of response strategies. The results of a survey of alliance managers corroborate the circumplex structure of response strategies and demonstrate that previously discarded antecedents actually have significant effects on response strategies if we adopt the circumplex structure.

The managerial implications derived from the findings show that managers account for the integrated structure of response strategies when making decisions and consider influential factors at the individual, alliance and environmental levels of analysis. They perform this assessment rather than choosing a response strategy in piecemeal fashion based solely on alliance-level factors, as implied by previous studies. This study's insights help managers better anticipate the response behavior of their alliance partners and thus contribute to a clearer understanding of managers' complex decision-making processes in strategic alliances.

In the next section, we review response strategy literature and then develop a model of response strategies. After we present the method used to empirically assess the model, we detail our results. Finally, we conclude this article with a discussion of the methodological, theoretical, and managerial implications and limitations.

\section{A model of response strategies in strategic alliances}

\section{Seven response strategies}

A response strategy is a manager's intended reaction to relationship dissatisfaction (Tjemkes and Furrer, 2010; Tjemkes et al., 2012). Hirschman (1970) proposed a framework in which exit, voice and loyalty represent three alternative response strategies organized along a constructive-destructive dimension. Farrell (1983) extended this framework with neglect and a second passive-active dimension, proposing the EVLN (exit-voice-loyalty-neglect) typology. Later studies distinguished three types of voice: considerate, creative and aggressive (Hagedoorn et al., 1999; Tjemkes and Furrer, 2010; Zhou and George, 2001), which vary according to their degree of activeness and constructiveness. Opportunism also joined the typology (Ping, 1993), as an active-destructive strategy.

Exit refers to the termination of an alliance and is the most destructive response (Rusbult et al., 1982). It also constitutes a marginally active response (Hagedoorn et al., 1999; Tjemkes et al., 2012). Opportunism is an active-destructive response (Wathne and Heide, 2000) to increase benefits from the alliance in ways that are prohibited in the alliance contract (Ping, 1993). Considerate voice is an active-constructive response to improve the alliance relationship by communicating in a relationship-preserving manner and cooperatively discussing problems with one's partner (Hagedoorn et al., 1999; Ping, 1993). Compared to considerate voice, aggressive voice is more active-destructive. It is the forceful imposition of views on partners without making any attempt to avoid conflicts (Hagedoorn et al., 1999; Hibbard et al., 2001). Creative voice is the generation of innovative and potentially useful solutions to solve issues in the alliance relationship (Zhou and George, 2001). This makes it constructive and more active than considerate voice (Furrer et al., 2012). Patience is the response strategy of a partner silently accepting the issues in the belief that the alliance will improve in the future (Ping, 1993). Patience is passive-constructive because it involves voluntarily ignoring the issue in the hope that the situation will resolve itself. Finally, neglect is 
passive-destructive because it allows the alliance relationship to deteriorate (Farrell, 1983; Rusbult et al., 1982). Neglect is based on the belief that the alliance does not deserve to be salvaged, so little effort is spent to keep it afloat (Ping, 1993).

\section{The circumplex structure of response strategies}

Building on the passive-active and constructive-destructive two-dimensional space, Furrer et al. (2012) empirically demonstrated that a circumplex structure best represents the interrelationships among response strategies. A circumplex structure organizes response strategies along the circumference of a circle on the basis of the degree of compatibility and incompatibility (Fabrigar et al., 1997). For example, aggressive voice and opportunism are both active-destructive, so are compatible and located close to each other on the circle. By comparison, neglect (passive-destructive) and creative voice (active-constructive) are incompatible, so are located opposite each other. Figure 1 depicts the response strategies circumplex structure.

As mentioned in the introduction, a key property of a circumplex structure is that it is continuous (Schwartz, 2012) and could account for additional unmeasured response strategies that blend the existing strategies (Hagedoorn et al., 1999). There could be unmeasured strategies between any pair of response strategies (Furrer et al., 2012). An important implication of such a continuous structure is that there may be antecedents that are related to unmeasured interstitial response without showing a significant effect on any measured response strategy or any of the two dimensions of the response strategy space. Therefore, modeling response strategies as a circumplex structure enables detection of effects that would be difficult to observe when using a discrete model of response strategies. Thus, it allows for a better prediction of response strategies by reducing Type II error.

\section{Response strategy antecedents}

Akin to previous alliance response strategy studies (e.g., Ping, 1993), we adopt a one-sided perspective on the relationship (Kumar et al., 1993) focusing on one partner's response behavior. Based on this perspective, we develop a model explaining an alliance manager's response preference (see Figure 2). More specifically, we formulate hypotheses specifying relationships between three sets of antecedents-individual, alliance and environmental factors-and the degree of passiveness-activeness and constructiveness-destructiveness of response strategies, while accounting for the circumplex structure.

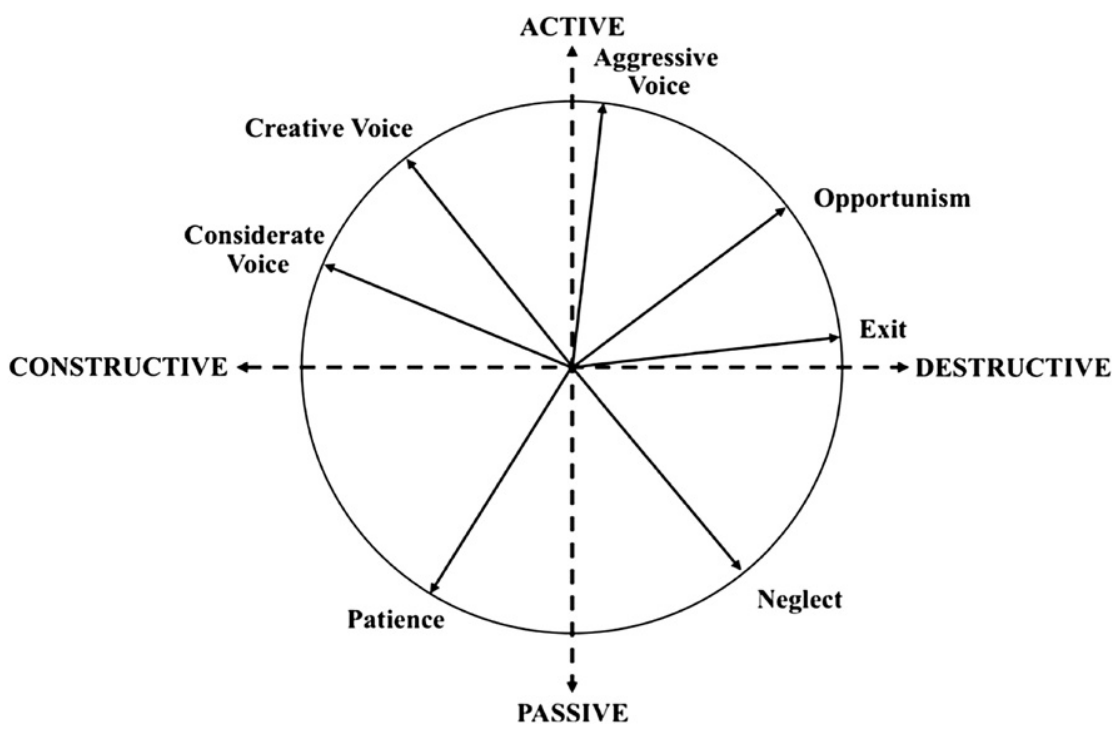

Figure 1. The theoretical circumplex structure of response strategies 


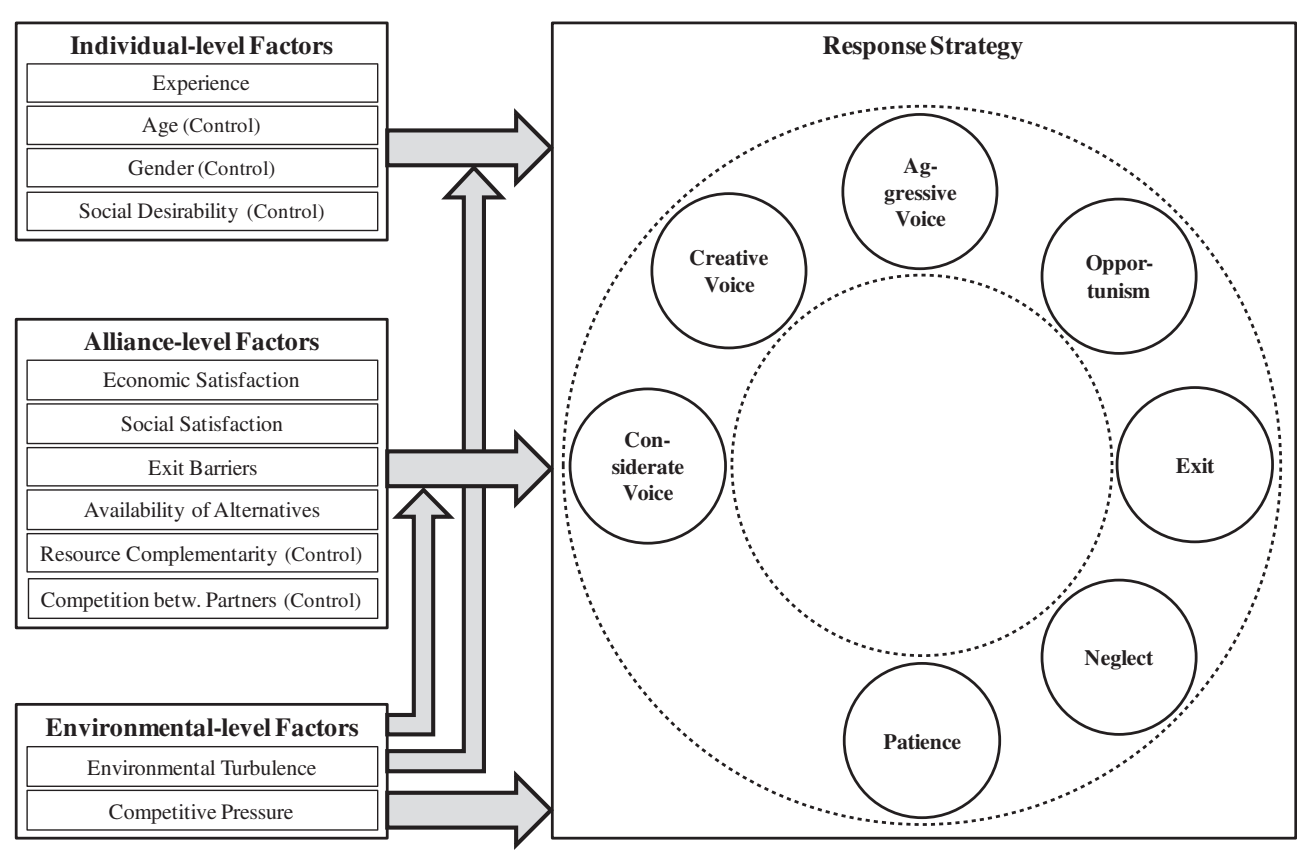

Figure 2. Model of response strategies

\section{Individual factor: alliance experience}

Managers are bounded in their rationality, and their decisions are based on heuristics and cues, partly influenced by their experience (Hambrick and Mason, 1984). Their cognitive bases and values filter and distort their perceptions, and thereby affect decision-making (Pansiri, 2005). Thus, at the individual level, alliance manager characteristics are likely to constitute an antecedent of response strategy preference. In this study, we focus on one such critical personal characteristic, a manager's experience with strategic alliances (Tjemkes et al., 2012). This is because personal and demographic characteristics, such as functional background and cultural values, are embedded in a manager's experience (Hambrick and Mason, 1984).

Alliance experience refers to a manager's know-how obtained through past alliance engagements (Hoang and Rothaermel, 2005). Experience may be built up through hands-on management of multiple relationships, participating in alliance communities, and having received alliance training and education (Parise and Sasson, 2002). For example, communities of practice enhance managers' intellectual capital, which they can leverage. Similarly, training and education enables managers to learn from other managers' experiences. Managers' alliance experience increases their comprehension of the complexities inherently tied to the management of strategic alliances. Pekar and Allio (1994) showed that, compared to inexperienced managers, experienced alliance managers are better able to identify business risks, develop feasible business plans, link resources to strategic priorities, conduct resource planning, and couple incentives and performance metrics. Moreover, experienced alliance managers are better capable to address difficulties should they arise. They recognize adverse situations in a timely manner and implement initiatives to steer the alliance away from premature termination (Pekar and Allio, 1994). That is, building on their experience they are likely to use active-constructive responses to avoid conflict, and quickly identify and competently resolve problematic alliance situations. In contrast, managers with little experience are likely to be unable to deal with emerging tensions and default to passive-destructive responses:

Hypothesis 1: A manager's alliance experience positively influences his/her preference for active-constructive responses. 


\section{Alliance-level factors: exchange conditions}

Building on social exchange and interdependence theories, prior response strategy research (Rusbult and Farrell, 1983; Rusbult et al., 1988) proposed that response strategies are influenced by relationship- or alliance-level factors. In line with prior alliance studies (Geyskens and Steenkamp, 2000; Ping, 1993; Tjemkes and Furrer, 2010), we focus on four alliance-level factors, economic satisfaction, social satisfaction, exit barriers, and availability of alternatives, which have been identified to affect managers' preference for certain response strategies.

Economic satisfaction pertains to evaluation of the strategic alliance's financial outcomes (Geyskens and Steenkamp, 2000). Economically satisfied managers prefer active-constructive responses because good financial performance increases partners' commitment to the alliance (Olk and Young, 1997). When economic performance is low, managers are likely to prefer passivedestructive strategies to escape the underperforming relationship (Brouthers and Bamossy, 2006). Social satisfaction pertains to managers' evaluations of the psycho-social aspects of the alliance (Geyskens and Steenkamp, 2000). Managers who are satisfied with the alliance relationship tend to appreciate contact with their counterparts and are likely to be more tolerant of problematic situations. They are more likely to prefer passive-constructive response strategies (Hibbard et al., 2001). Managers who are dissatisfied with the relationship prefer active-destructive strategies and would rather attempt to covertly extract benefits or discontinue the relationship than try to save it (Deeds and Hill, 1998). Exit barriers refer to the costs of exiting a strategic alliance (Ping, 1999). Exit barriers, such as alliance-specific investments, are likely to trigger active responses and inhibit passive strategies. Active responses might reduce the risk of losing the investments if the relationship is prematurely terminated (Ping, 1993). Availability of alternatives pertains to the extent to which partners possess other options to achieve their objectives. When there is no alternative, managers have strong incentives to make the current alliance work and are likely to actively respond to improve the situation (Ping, 1999). When a firm has attractive alternatives at hand, the need to preserve existing alliances diminishes, which allows for more passive responses. Therefore:

Hypothesis 2: Exchange conditions influence a manager's response strategy preference such that (a) economic satisfaction positively influences preference for active-constructive responses; (b) social satisfaction positively influences preference for passive-constructive responses; (c) the presence of exit barriers positively influences preferences for active responses; and (d) the availability of alternatives positively influences preference for passive responses.

\section{Environmental factors: environmental turbulence and competitive pressure}

Drawing on industrial organization economics (e.g., Porter, 1980; Scherer and Ross, 1990), alliance research has shown that the industry environment can exercise direct and moderating effects on strategic decision-making. As firms establish alliances to respond to the external industry environment (Paulraj and Chen, 2007), this external environment affects alliance decision-making, including response strategies. As suggested by Tjemkes and Furrer (2011), we distinguish between two environmental factors: environmental turbulence and competitive pressure.

Environmental turbulence pertains to volatility or difficult-to-predict discontinuities in a firm's industry (Aldrich, 1979). Turbulent environments are characterized by unpredictability, unexpected changes, and the absence of patterns (Fynes et al., 2004). In a turbulent industry, firms are more likely to switch partners to respond to changes (Aldrich, 1979) proactively adapting their resources to new environmental requirements (Kandemir et al., 2006). In such environments, the consequences of discontinuing an alliance tend to be less severe, thus firms may also be less inclined to avoid conflict with their alliance partners. They are more likely to prefer active-destructive response strategies. In contrast, stable environments are more predictable and firms have more opportunities to exploit their alliance partners' resources. In such environmental conditions, alliance partners are likely to prefer response strategies that minimize conflict (Kandemir et al., 2006), thus it is more likely they will prefer passive-constructive strategies. 
Competitive pressure refers to the degree of rivalry between competitors in an industry. When firms operate in industries characterized by high competitive pressure, they are under continuous threat from rivals (Furrer and Thomas, 2000). In such an environment, they are more willing to put the alliance relationship at risk through passive-destructive response strategies. For example, firms are more likely to refrain from investing in their existing alliances in order to save resources to counter rivals' moves. In contrast, firms operating under less competitive pressure are likely to preserve the quality of their existing alliances to leverage resources, because they are likely to have developed a state of mutual forbearance with their rivals (Axelrod, 1986). In such an environment, firms can improve alliance performance without the risk that competitors' actions will render the relationship obsolete. To ensure stable alliance development, they need to secure partner involvement. This suggests preferences for active-constructive strategies. Thus:

Hypothesis 3: Environmental factors influence a manager's response strategy preference such that (a) environmental turbulence positively influences preference for active-destructive responses; and (b) competitive pressure positively influences preferences for passive-destructive responses.

The industry environment has also been identified as a major contingency in management and strategy research (Porter, 1980; Scherer and Ross, 1990). More specifically, environmental turbulence and competitive pressure are likely to increase requirements for successful management (Calantone et al., 2003), as they are likely to interact with individual- and alliance-level factors. We propose that, in turbulent and competitive environments, managers' alliance experience is likely to be more critical than in less turbulent and competitive environments. The more turbulent and competitive, the environment the more varied and fragmented the nature of alliance managers' work (Mintzberg, 1973) and the greater the information-processing demand on managers (Daft et al., 1988). Confronted with such external pressures, alliance experience enables managers to more efficiently and effectively process information, providing managers with more latitude to engage in active-constructive responses. In contrast, in less turbulent and less competitive environments, alliance experience is likely to be less critical, because inexperienced managers have more time to analyze and respond to the situation. Thus, environmental turbulence and competitive pressure strengthen the relationship between alliance experience and response strategy preference.

Consistent with strategic issues categorization theory (Dutton and Jackson, 1987), in turbulent and competitive environments managers are likely to focus their attention on economic and social satisfaction, because in such environments any change in these factors is likely to be perceived as a threat. Managers perceive economic and social dissatisfaction as more critical factors, because adversities need to be dealt with quickly. In contrast, in less turbulent and competitive environments, economic and social satisfaction constitute less influencing factors, as alliance managers can adopt a longer-term perspective. Thus, both environmental turbulence and competitive pressure strengthen the effects of economic and social satisfaction on response strategy preference.

Alternatively, in less turbulent and competitive environments managers are likely to focus their attention on exit barriers and available alternatives. In such environments, managers consider exit barriers and the lack of alternatives as threats, thus these factors become more important. In contrast, in turbulent and competitive environments, the importance of exit barriers and available alternatives relatively diminishes, as opportunities may become obsolete and future, unforeseen opportunities may provide managers with new attractive alternatives. This implies that both environmental turbulence and competitive pressure weaken the relationship between exit barriers and available alternatives and response strategy preference. In sum, we hypothesize:

Hypothesis 4 and 5: Environmental turbulence (H4) and competitive pressure (H5) moderate the relationship between individual and alliance factors and manager's response strategy preference such that they (a) strengthen the effect of alliance experience on response strategy preference, (b) strengthen the effect of economic and social satisfaction on response strategy preference, and (c) weaken the effect of exit barriers and available alternatives on response strategy preference. 


\section{Data and methods}

\section{Study setting and procedure}

We test the hypotheses in the context of non-equity strategic alliances. As we focus on a manager's preference for response strategies, the unit of analysis in the study is an alliance manager responsible for an alliance. To collect data, we developed an online survey and contacted CEOs of small and medium enterprises (SMEs). Contact details were obtained from a business association. The key advantage of targeting SME CEOs is that they tend to be directly responsible and/or involved in the management of their firm's strategic alliances unlike those of larger firms. This ensures the quality of the data.

The survey asked respondents to select a non-equity strategic alliance with a clear financial objective with which they were personally involved. Then, respondents were asked to assess alliance and environmental factors pertaining to the selected alliance as well as individual and firm characteristics. Finally, we asked them to indicate how they would respond to the current situation in the selected alliance, rather than reporting on past behavior, to reduce recall and recency bias as well as social desirability bias.

A link to the survey was sent by e-mail to 1,000 CEOs. One hundred and six valid questionnaires were returned, for a response rate of $10.6 \%$, which is reasonable for a relatively long online survey (Deutskens et al., 2004). However, given the relative low response rate, response bias might be a concern. A comparison of respondents to a group of 36 non-respondents on the basis of firm size $(t=-.993, p=.332)$, number of alliances $(t=1.368, p=.174)$, and manager's age $(t=-1.245, p=.220)$ indicated no significant differences. Thus, response bias poses a limited concern in this study.

On average, respondents' firms had 433 employees (standard deviation [SD] $=1146.41$ ), and were currently participating in 7.9 alliances $(S D=8.8)$. The respondents were mostly male $(72.6 \%), 43.4$ years old $(\mathrm{SD}=10.6)$, and had moderate experience with alliances (4.06 on a seven-point scale, $\mathrm{SD}=1.88)$. The respondents worked for firms operating in business services (49), non-profit sectors (26), production/manufacturing (18), and other industries (13). We controlled for type of sector when we estimated the PLS models, but the results were not significant.

\section{Measures}

\section{Response strategies}

We use the scales developed and validated by Tjemkes and Furrer (2010). Appendix A presents the complete list of items. Exit was measured with items related to whether the respondent intended to end the relationship or stop doing business with the alliance partner. Measures for opportunism included: withholding information, exaggerating the severity of the situation, and escaping from contractual obligations. Aggressive voice referred to pushing the firm's solution on its partner, and being persistent. Creative voice referred to generating novel and creative solutions. Considerate voice items included: working to create a consensus, and finding a satisfactory solution acceptable for both partners. Patience was measured with items including: waiting for better times, and trusting that the situation would resolve itself. The items for neglect included: not dealing with the issue, not putting additional effort into the relationship, and not presenting initiatives to improve the situation. All constructs were operationalized by reflective multi-item measures using seven-point scales, ranging from "I would definitely not react in this way" (1) to "I would definitely react in this way" (7).

\section{Individual factor}

Alliance experience pertains to a manager's ability (that is, knowledge and skills) to handle alliance relationships (Hoang and Rothaermel, 2005). One item captured alliance experience: "To what extent do you have experience with alliances?" The indicator used a seven-point scale, ranging from "Minimal experience" (1) to "Substantial experience" (7). 


\section{Alliance factors}

The four exchange variables were measured with existing and validated scales. Economic satisfaction was captured with two items that tapped into respondents' evaluation of the financial outcomes of the relationship (Geyskens and Steenkamp, 2000). They examined to what extent the respondent is satisfied with the financial benefits the alliance generated and the overall alliance performance. Social satisfaction was operationalized with two items capturing the degree to which interactions with the partner are fulfilling, gratifying, and easy (Geyskens and Steenkamp, 2000). Five items, developed by Ping (1999), were used to capture exit barriers, pertaining to the degree to which the firm could not terminate the alliance without substantial costs because of investments. The availability of alternatives refers to the extent to which a partner possesses solutions that could enable managers to attain their firms' objectives. This was captured with two items (Ping, 1993) measuring the extent to which a firm possessed alternative options to achieve its strategic objectives. All constructs used sevenpoint scales.

\section{Environmental factors}

To capture environmental turbulence, we adapted the reflective scale developed by Slater and Narver (1994). It consists of three items that capture the degree to which respondents perceive the external environment to be dynamic, consider the firm's industry to be turbulent, and view the external environment to be uncertain. Competitive pressure was captured with one item assessing the degree to which the alliance is surrounded by strong and direct competitors. Both constructs were measured with seven-point scales.

\section{Controls}

Prior research indicates that additional variables might also influence strategic alliance decisionmaking in general, such as resource complementarity and competition between partners. However, further theoretical development is needed to relate them to preferences for response strategies and therefore predictions at this stage are not warranted. Thus, we do not propose specific hypotheses but control for their potential effects. That is, we controlled for resource complementarity, which refers to the degree to which the combination of the partner's resource endowments would result in synergies (Lambe et al., 2002). We also controlled for whether respondents perceived their partners as competitors, because an alliance between competitors might be subject to additional tensions (Kumar and Nti, 2004). In addition, as some response strategies (such as opportunism) may be less socially desirable than others, the M-C2 version of the Marlowe-Crowne Social Desirability scale was also included (Strahan and Gerbasi, 1972). We also controlled for managers' age and gender.

\section{Analysis}

We enhance and use PLS path modeling to assess the circumplex structure of response strategies and to test our hypotheses. Since PLS does not provide a global goodness-of-fit measure (Henseler and Sarstedt, 2012), we use a three-step procedure to assess the adequacy of the model (see Anderson and Gerbing, 1988). First, we assess the measurement model with regard to reliability, validity, and circumplexity (Furrer et al., 2012). Second, we test the structural model parameters of the discrete two-dimensional and continuous circumplex models. Third, we compare the explanatory power of the two models.

\section{Measurement model}

The reliability and validity of the constructs' measurement was assessed based on Hair et al. (2012) and Henseler et al.'s (2009) recommendations. Then, we examined the circumplexity of the response strategy structure. 


\section{Reliability}

The internal consistency reliability was estimated using Cronbach's alpha $(\alpha)$ and Jöreskog's rho $\left(\rho_{\mathrm{c}}\right)$. The $\alpha$ is typically lower bound to reliability, whereas $\rho_{\mathrm{c}}$ (which relies on PLS' upwardsbiased construct loadings, see Gefen et al., 2011) overestimates the reliability. Therefore, the true construct reliability is likely to lie between $\alpha$ and $\rho_{\mathrm{c}}$. Based on reliability considerations, six indicators were discarded (see Appendix A for the final list of indicators and their standardized loadings). As Table 1 shows, all constructs exhibited sufficient levels of internal consistency reliability with $\alpha$ coefficients above .70 (two exceptions with $\alpha \geq .63$ ) and $\rho_{\mathrm{c}}$ coefficients above .80 (see Nunnally, 1978).

\section{Validity}

The validity of the construct measurement was assessed in terms of convergent and discriminant validity (Hair et al., 2012; Henseler et al., 2009). Convergent validity was assessed using the average variance extracted (AVE). All AVE values are above the critical value of .50 (Fornell and Larcker, 1981), which indicates that all constructs were unidimensional. Table 1 shows the AVE values and the construct correlations. A comparison of the squared construct correlation (.48 between economic and social satisfaction) with the smallest AVE (.50 of neglect) showed that the FornellLarcker criterion was met. Therefore, discriminant validity can also be confirmed.

\section{Circumplexity}

The two passive-active and constructive-destructive dimensions of the structure were modeled first to assess the circumplex structure of response strategies. An enhanced hierarchical component model (depicted in Appendix B) was estimated to validate these two dimensions, using the repeated-indicator approach (Wetzels et al., 2009; Ringle et al., 2012) in combination with the factor-weighting scheme (Lohmöller, 1989). We relied on deflation as a sequential estimation approach (Lohmöller, 1989), which implied two estimation rounds. The first round estimated the loadings of the first dimension of response strategies. The second round used the measurement residuals of the first dimension as indicators for the second component. This makes it possible to identify two orthogonal dimensions.

The hierarchical component model was enhanced by an orthogonal component rotation, including sign constraints. The PLS algorithm ${ }^{1}$ was extended to determine the angle $\varphi$ between the first higher-order dimension and the exit construct. Both higher-order dimensions of response strategies were then orthogonally rotated using the following rotation matrix:

$$
R_{-\varphi}=\left(\begin{array}{cc}
\cos \varphi & \sin \varphi \\
-\sin \varphi & \cos \varphi
\end{array}\right)
$$

Moreover, the first higher-order dimension was multiplied with the sign of the correlation with the exit construct. The second higher-order dimension was multiplied with the sign of the correlation with the aggressive voice construct. This procedure circumvented sign indeterminacy and ensured that the first dimension of the response strategy space (constructive-destructive) was equal to the exit construct, whereas the second dimension represented the passive-active dimension. Table 2 lists the path coefficients of the paths from the two dimensions to the seven response strategies as polar coordinates. For each response strategy, radius $r$ was obtained as the Euclidean distance from the origin

$$
r=\sqrt{b_{1}^{2}+b_{2}^{2}}
$$

\footnotetext{
${ }^{1}$ We programmed this extension as part of an implementation of the PLS path modeling algorithm in R 2.14.1 (R Development Core Team, 2011). Results obtained by the R-based implementation of the standard PLS algorithm were equal to results obtained by SmartPLS 2.0 M3 (Ringle et al., 2005). The R code is available from the third author upon request.
} 


\section{$\begin{array}{llllll}\text { Construct } & \text { Items } & \alpha & \rho_{\mathrm{c}} & \text { AVE } & \text { Correlations }\end{array}$}

$\begin{array}{llllllllllllllllll}1 & 2 & 3 & 4 & 5 & 6 & 7 & 8 & 9 & 10 & 11 & 12 & 13 & 14 & 15 & 16 & 17 & 18\end{array}$

\begin{tabular}{|c|c|c|c|c|c|c|c|c|c|c|c|c|c|c|c|c|c|c|c|c|c|c|c|}
\hline 1 & Age & 1 & - & - & - & 1.00 & & & & & & & & & & & & & & & & & \\
\hline 2 & Aggressive Voice & 4 & .75 & .84 & .57 & .06 & 1.00 & & & & & & & & & & & & & & & & \\
\hline 3 & $\begin{array}{l}\text { Availability of } \\
\text { Alternatives }\end{array}$ & 2 & .63 & .84 & .72 & -.08 & .08 & 1.00 & & & & & & & & & & & & & & & \\
\hline 4 & $\begin{array}{l}\text { Competition } \\
\text { between Partners }\end{array}$ & 1 & - & - & - & .21 & .11 & .10 & 1.00 & & & & & & & & & & & & & & \\
\hline 5 & $\begin{array}{l}\text { Competitive } \\
\text { Pressure }\end{array}$ & 1 & - & - & - & -.06 & .02 & .12 & .33 & 1.00 & & & & & & & & & & & & & \\
\hline 6 & $\begin{array}{l}\text { Considerate } \\
\text { Voice }\end{array}$ & 5 & .88 & .91 & .67 & .14 & .22 & .06 & .09 & -.28 & 1.00 & & & & & & & & & & & & \\
\hline 7 & Creative Voice & 5 & .81 & .87 & .57 & .10 & .45 & .11 & .09 & -.20 & .54 & 1.00 & & & & & & & & & & & \\
\hline 8 & $\begin{array}{l}\text { Economic } \\
\text { Satisfaction }\end{array}$ & 2 & .84 & .92 & .86 & -.09 & .05 & .19 & -.07 & -.07 & .35 & .32 & 1.00 & & & & & & & & & & \\
\hline 9 & $\begin{array}{l}\text { Environmental } \\
\text { Turbulence }\end{array}$ & 3 & .73 & .85 & .65 & .03 & -.05 & -.02 & .29 & .16 & -.14 & .00 & -.26 & 1.00 & & & & & & & & & \\
\hline 10 & Exit & 4 & .90 & .93 & .77 & .00 & .11 & -.10 & -.01 & .13 & -.45 & -.30 & -.62 & .13 & 1.00 & & & & & & & & \\
\hline 11 & Exit Barriers & 5 & .82 & .87 & .58 & .00 & .22 & -.21 & -.03 & .00 & .09 & .04 & -.11 & .20 & .12 & 1.00 & & & & & & & \\
\hline 12 & Experience & 1 & - & - & - & .24 & .08 & .01 & .02 & -.22 & .27 & .34 & .08 & .15 & -.28 & .06 & 1.00 & & & & & & \\
\hline 13 & Gender & 1 & - & - & - & -.26 & -.12 & .04 & -.19 & .22 & -.31 & -.10 & -.08 & -.05 & .15 & -.02 & -.21 & 1.00 & & & & & \\
\hline 14 & Neglect & 4 & .66 & .80 & .50 & .00 & -.12 & -.03 & .03 & .29 & -.45 & -.36 & -.36 & -.02 & .53 & -.07 & -.19 & .07 & 1.00 & & & & \\
\hline 15 & Opportunism & 6 & .85 & .89 & .57 & -.27 & .10 & -.16 & -.03 & .25 & -.36 & -.25 & -.05 & .13 & .21 & .23 & -.20 & .06 & .16 & 1.00 & & & \\
\hline 16 & Patience & 6 & .85 & .89 & .57 & .05 & -.43 & .03 & -.04 & .02 & -.19 & -.29 & -.01 & -.18 & -.01 & -.29 & -.07 & .05 & .35 & .00 & 1.00 & & \\
\hline 17 & $\begin{array}{l}\text { Resource } \\
\text { Complementarity }\end{array}$ & 5 & .85 & .89 & .63 & .13 & .28 & .11 & .05 & -.20 & .47 & .49 & .40 & .08 & -.55 & .01 & .30 & -.15 & -.47 & -.17 & -.16 & 1.00 & \\
\hline 18 & Social Desirability & 1 & - & - & - & .26 & -.07 & .15 & -.12 & -.33 & .05 & -.01 & .04 & .01 & .00 & -.11 & .01 & -.23 & -.16 & -.27 & .05 & .01 & 1.00 \\
\hline 19 & Social Satisfaction & 2 & .78 & .90 & .82 & .02 & .01 & .18 & -.03 & -.29 & .45 & .38 & .69 & -.18 & -.64 & -.18 & .17 & -.22 & -.36 & -.21 & .07 & .56 & .13 \\
\hline
\end{tabular}

Notes: $n=106$. Correlations with absolute value greater than .19 are significant at $5 \%$. 
Table 2. Polar coordinates of response strategies, their confidence intervals, and differential angles

\begin{tabular}{|c|c|c|c|c|c|c|c|c|c|}
\hline & \multirow[t]{2}{*}{$r$} & \multicolumn{2}{|c|}{ 95\%-CI $(r)$} & \multirow[t]{2}{*}{$\varphi$} & \multicolumn{2}{|c|}{ 95\%-CI $(\varphi)$} & \multirow[t]{2}{*}{$\Delta \varphi$} & \multicolumn{2}{|c|}{ 95\%-CI $(\Delta \varphi)$} \\
\hline & & $\begin{array}{l}\text { Lower } \\
\text { bound }\end{array}$ & $\begin{array}{l}\text { Upper } \\
\text { bound }\end{array}$ & & $\begin{array}{l}\text { Lower } \\
\text { bound }\end{array}$ & $\begin{array}{l}\text { Upper } \\
\text { bound }\end{array}$ & & $\begin{array}{l}\text { Lower } \\
\text { bound }\end{array}$ & $\begin{array}{l}\text { Upper } \\
\text { bound }\end{array}$ \\
\hline Exit & .778 & .584 & .945 & $0^{\circ}$ & - & - & $4^{\circ}$ & $-98^{\circ}$ & $64^{\circ}$ \\
\hline Opportunism & .623 & .376 & .911 & $4^{\circ}$ & $262^{\circ}$ & $64^{\circ}$ & $77^{\circ}$ & $44^{\circ}$ & $205^{\circ}$ \\
\hline Aggressive Voice & .769 & .444 & .879 & $81^{\circ}$ & $57^{\circ}$ & $156^{\circ}$ & $48^{\circ}$ & $9^{\circ}$ & $73^{\circ}$ \\
\hline Creative Voice & .786 & .691 & .887 & $129^{\circ}$ & $99^{\circ}$ & $182^{\circ}$ & $23^{\circ}$ & $-19^{\circ}$ & $51^{\circ}$ \\
\hline Considerate Voice & .840 & .543 & .900 & $152^{\circ}$ & $122^{\circ}$ & $189^{\circ}$ & $111^{\circ}$ & $91^{\circ}$ & $175^{\circ}$ \\
\hline Patience & .855 & .596 & .937 & $263^{\circ}$ & $237^{\circ}$ & $321^{\circ}$ & $60^{\circ}$ & $3^{\circ}$ & $90^{\circ}$ \\
\hline Neglect & .680 & .517 & .858 & $323^{\circ}$ & $291^{\circ}$ & $357^{\circ}$ & $37^{\circ}$ & $3^{\circ}$ & $69^{\circ}$ \\
\hline
\end{tabular}

where $b_{1}$ is the path coefficient from the constructive-destructive dimension and $b_{2}$ is the path coefficient from the passive-active dimension. The corresponding angle $\varphi\left(0^{\circ} \leq \varphi<360^{\circ}\right)$ was obtained by

$$
\varphi=\operatorname{sgn}\left(b_{2}\right) \cdot\left(\cos ^{-1}\left(b_{1} / r\right)-180^{\circ}\right)+180^{\circ}
$$

The 95\% confidence intervals for radii and angles were determined by means of bootstrapping with 10,000 bootstrap samples, leading to resampling-based confidence regions (see Obenchain, 1999). Moreover, bootstrap confidence intervals were obtained for the angle differences $(\Delta \varphi)$ between neighboring response strategies (see Table 2).

We extended the hierarchical component model with the social desirability measure to control for social desirability bias. As anticipated, social desirability bias negatively affected opportunism $(\beta=-.177, p<.05)$, which meant that opportunism would have been more pronounced if respondents had not been prone to social desirability.

The results support the circumplexity of response strategies. First, all radii were significantly different from zero. The smallest lower bound of a confidence interval of $\varphi$ was found for opportunism (.376). All confidence intervals of radii shared one subinterval $(.691 ; .849)$, which is satisfactory (Fabrigar et al., 1997). Second, six out of seven response strategies are positioned on the circumference of the circle (i.e. equal radii) with only opportunism deviating from the circumference. Third, the point estimates are arranged around the origin in the order predicted in Figure 1. Fourth, five out of seven differences between angles were significantly different from zero. Only opportunism and exit and considerate and creative voice did not significantly differ from each other. Although these two non-significant differences in angles did not support the existence of seven distinct strategies, they did not reject the circumplex structure of response strategies (Furrer et al., 2012; Schwartz, 2012). Overall, the results provide evidence for a circumplex structure of response strategies. To corroborate the PLS findings we used co-variance based structural equation modeling to assess a discrete two-dimensional model and two circumplex models, a fully constrained model and a model for which we released the equality constraint for the radius of opportunism. The results confirm the PLS findings (see Appendix C).

Figure 3 summarizes the findings with regard to the circumplexity of response strategies. First, it shows the point estimates of the seven response strategies. Second, it includes the confidence regions, which are annular sectors (in dotted lines) representing the confidence intervals of angles and radii. Third, it contains a grey annulus symbolizing the subset of radii that all confidence intervals of response strategy radii have in common.

\section{Structural model results}

The model was estimated as depicted in Figure 2. To avoid possible problems of non-convergence, the factor-weighting scheme was chosen, and the centroid scheme was used for triangulation (Henseler, 2010). No differences were found. Moreover, 10,000 bootstrap samples were used to 


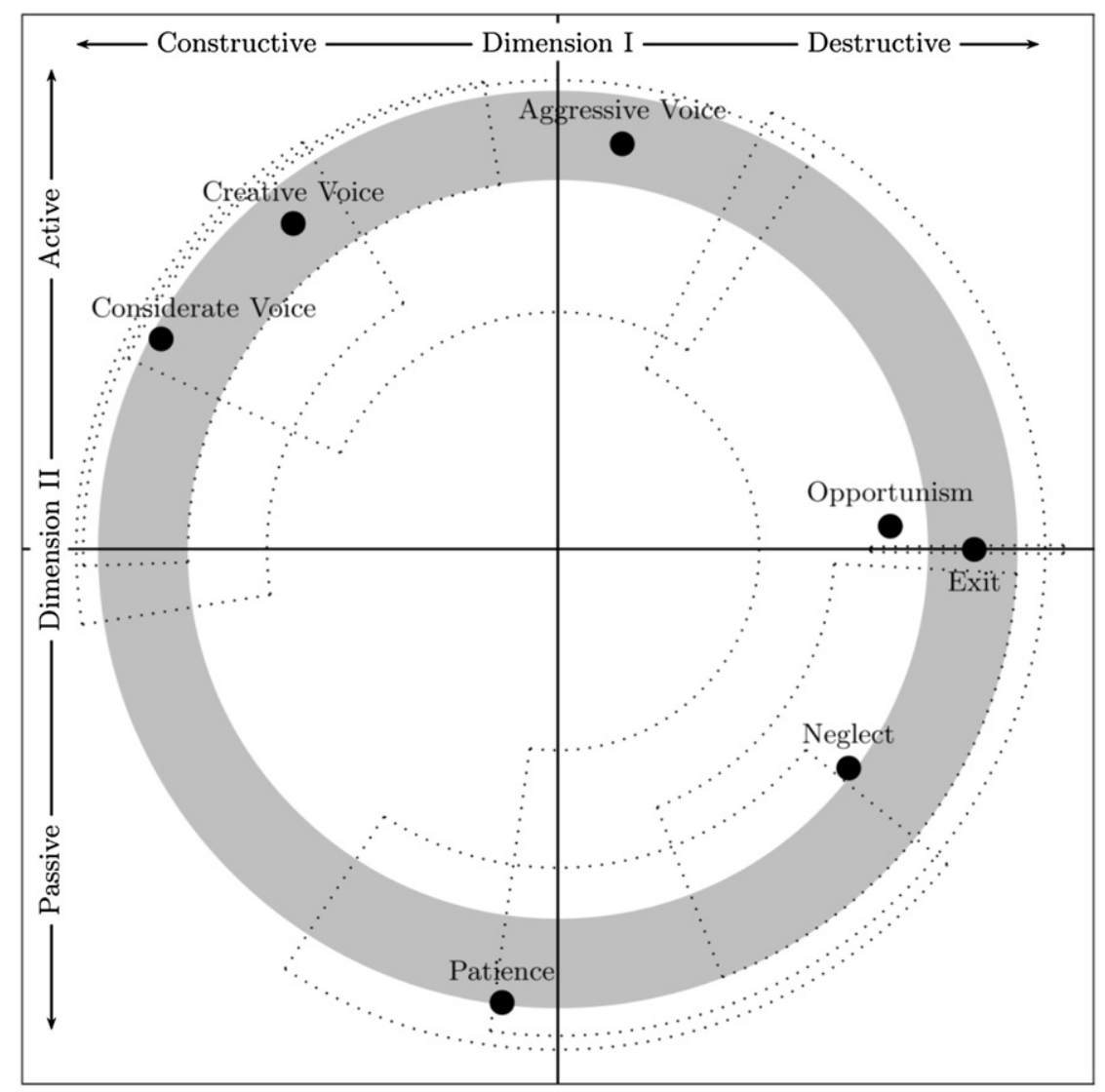

Note: The dotted annular sectors represent the confidence regions. The grey annulus marks the subset of radii that all sectors have in common.

Figure 3. The empirical circumplex structure of response strategies

obtain inference statistics. Since nothing is known about the behavior of sign correction mechanisms in the light of a circumplex structure, we did not use sign corrections. Consequently, the resulting inference statistics can be regarded as somewhat conservative.

A hybrid orthogonalizing approach helped analyze moderating effects (Henseler and Chin, 2010; Henseler et al., 2012). Orthogonalization (also called residuals centering) means that instead of simply multiplying the interacting variables, the product of the interacting variables is regressed on the two original variables. The residuals serve as interaction term (Lance, 1988). Orthogonalization eliminates potential problems of multicollinearity that are often encountered in analyses of moderating effects (Cronbach, 1987). It also facilitates interpretation of regression coefficients in that single effects resulting from a regression with moderating effects strongly resemble main effects obtained from a model without moderating effects (Lance, 1988). Hybrid refers to the fact that scores for the interaction term are approximated in each iteration of the PLS algorithm (Henseler and Chin, 2010), which is the original approach proposed by Wold (1982) to incorporate nonlinear effects into PLS path models. In contrast to other approaches (see Goodhue et al., 2007), the hybrid approach does not capitalize on chance.

The model explains a substantial proportion of variance of the two dimensions of response strategies. The $R^{2}$ value of the constructive-destructive dimension (Dimension I) is .603, while the $R^{2}$ value of the passive-active dimension (Dimension II) is .379, resulting in an average value of .491 . The bias-corrected $95 \%$ bootstrap confidence intervals (see Henseler et al., 2009) of the $R^{2}$ values are $(.435 ; .725)$ and $(.208 ; .562)$, respectively. 


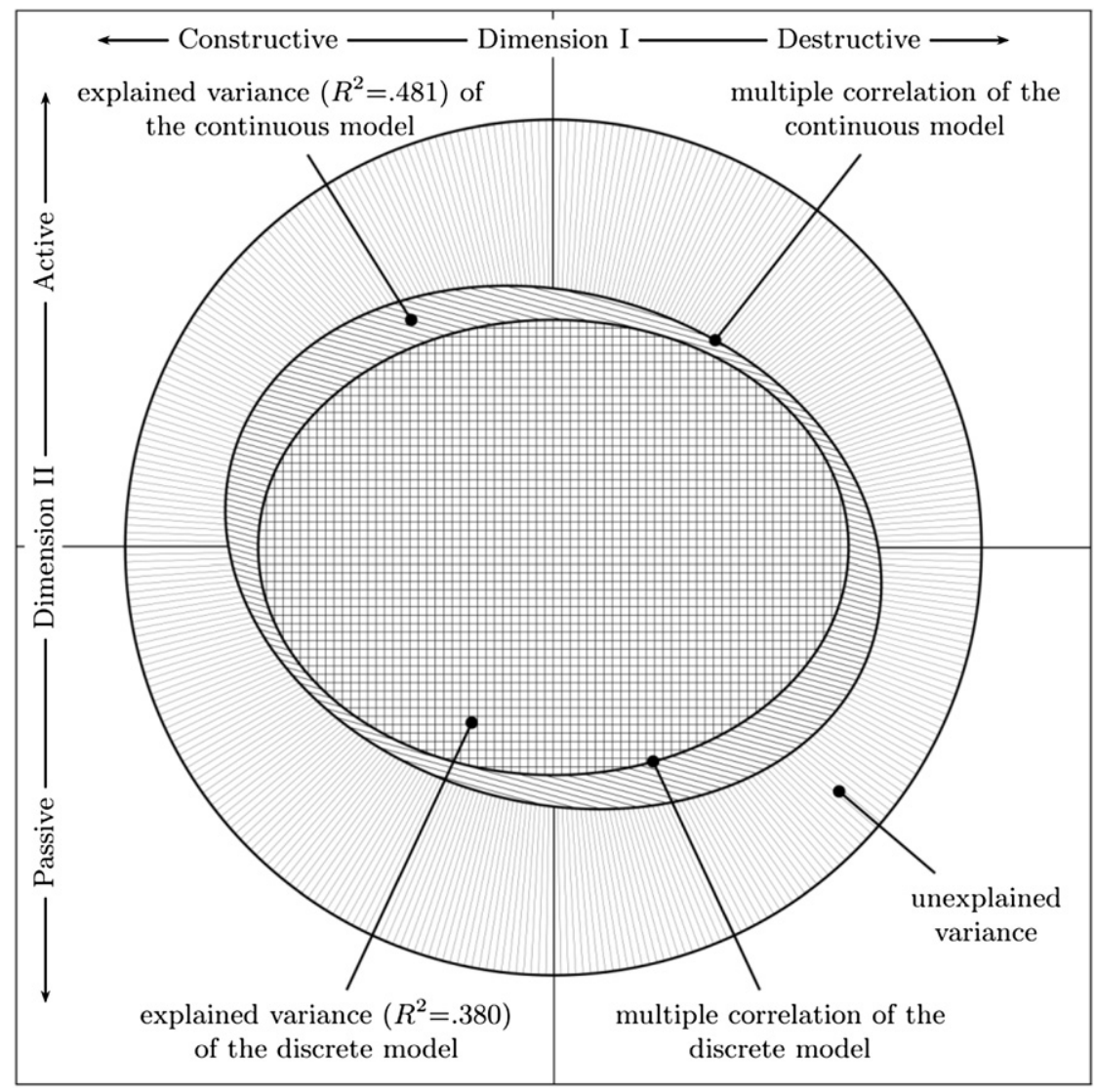

Figure 4. Explained variance of the discrete and continuous models

The results of the hypothesis testing are presented in Table 3. Alliance experience, as an individual factor, only had a significant effect on the constructive-destructive dimension $(\beta=-.184$, $t=-2.068)$. The significant radius in combination with an angle of $160^{\circ}(p<.05$ between $126^{\circ}-197^{\circ}$ ) supports the notion that high alliance experience mainly induces a constructive response. Low alliance experience mainly induces a destructive response at an angle of $340^{\circ}$ $\left(p<.05\right.$ between $\left.306^{\circ}-17^{\circ}\right)$. The findings thus provide mixed support for Hypothesis 1 , as the effect of alliance experience only influences the constructive-destructive dimension but not the passive-active dimension. Figure $5 \mathrm{a}$ visualizes the confidence region of the effect of experience.

Exchange conditions, such as alliance factors, also influence a manager's response strategy preference. Economic satisfaction only has a significant effect on the constructive-destructive dimension $(\beta=-.228, t=-1.842)$. The significant radius in combination with an angle of $157^{\circ}(p<.05$ between $133^{\circ}$ and $190^{\circ}$ ) supports the notion that high economic satisfaction mainly induces a constructive response. Low economic satisfaction has an effect on destructive responses at an angle of $337^{\circ}\left(p<.05\right.$ between $313^{\circ}$ and $\left.10^{\circ}\right)$. Hypothesis $2 \mathrm{a}$ is thus partially supported. Figure $5 \mathrm{~b}$ shows the confidence region of economic satisfaction. Social satisfaction does not exhibit any significant effect on either of the two dimensions. However, effects between $188^{\circ}$ and $244^{\circ}$ are significant, which implies that high social satisfaction positively influences preference for passive-constructive responses. Low social satisfaction induces active-destructive responses between $8^{\circ}$ and $64^{\circ}$. Hypothesis $2 \mathrm{~b}$ is thus supported. Figure $5 \mathrm{c}$ visualizes the confidence region of social satisfaction. Exit barriers have a significant effect on the passive-active dimension of response strategies $(\beta=.266, t=2.072)$, in that the presence of exit barriers positively influences preferences for active responses. The findings are inconclusive with regard to the influence on the constructive-destructive dimension. The significant radius in combination with an angle of $79^{\circ}(p<.05$ 


\begin{tabular}{|c|c|c|c|c|c|c|c|c|c|c|}
\hline \multirow[t]{4}{*}{ Hyp. } & \multirow[t]{4}{*}{ Independent Variable } & \multicolumn{4}{|c|}{ Discrete Analysis } & \multicolumn{5}{|c|}{ Continuous Analysis } \\
\hline & & \multicolumn{2}{|c|}{ Dimension I } & \multicolumn{2}{|c|}{ Dimension II } & \multicolumn{2}{|c|}{ Radius } & \multirow[t]{3}{*}{ Angle $^{a}$} & \multicolumn{2}{|c|}{$\begin{array}{l}\text { Angles between } \\
\text { which }|t|>1.645\end{array}$} \\
\hline & & \multicolumn{2}{|c|}{ Con-/Destructive } & \multicolumn{2}{|c|}{ Passive/Active } & \multirow[b]{2}{*}{$r$} & \multirow[b]{2}{*}{$t$-value } & & \multirow[b]{2}{*}{ Min } & \multirow[b]{2}{*}{$\operatorname{Max}$} \\
\hline & & $\beta$ & $t$-value ${ }^{\mathrm{b}}$ & $\beta$ & $t$-value & & & & & \\
\hline H1a & Alliance Experience & -.184 & -2.068 & .066 & .597 & .195 & 2.401 & $160^{\circ}$ & $126^{\circ}$ & $197^{\circ}$ \\
\hline $\mathrm{H} 2 \mathrm{a}$ & Economic Satisfaction & -.228 & -1.842 & .095 & .605 & .247 & 2.055 & $157^{\circ}$ & $133^{\circ}$ & $190^{\circ}$ \\
\hline $\mathrm{H} 2 \mathrm{~b}$ & Social Satisfaction & -.190 & -1.447 & -.242 & -1.297 & .307 & 2.074 & $232^{\circ}$ & $188^{\circ}$ & $244^{\mathrm{c}}$ \\
\hline $\mathrm{H} 2 \mathrm{c}$ & Exit Barriers & .054 & .494 & .266 & 2.072 & .271 & 2.679 & $79^{\circ}$ & $41^{\circ}$ & $128^{\circ}$ \\
\hline $\mathrm{H} 2 \mathrm{~d}$ & Available Alternatives & -.073 & -.716 & .051 & .456 & .090 & 1.172 & $145^{\circ}$ & - & - \\
\hline $\mathrm{H} 3 \mathrm{a}$ & Environmental Turbulence & .137 & 1.132 & -.016 & -.093 & .138 & 1.400 & $353^{\circ}$ & - & - \\
\hline \multirow[t]{2}{*}{$\mathrm{H} 3 \mathrm{~b}$} & Competitive Pressure & .142 & 1.291 & -.122 & -.872 & .187 & 2.065 & $319^{\circ}$ & $305^{\circ}$ & $347^{\circ}$ \\
\hline & Environmental Turbulence $\times$.. & & & & & & & & & \\
\hline $\mathrm{H} 4 \mathrm{a}$ & Alliance Experience & -.116 & -1.196 & .031 & .241 & .120 & 1.507 & $165^{\circ}$ & - & - \\
\hline $\mathrm{H} 4 \mathrm{~b}$ & Economic Satisfaction & .116 & .844 & .364 & 2.005 & .382 & 2.481 & $72^{\circ}$ & $30^{\circ}$ & $123^{\circ}$ \\
\hline $\mathrm{H} 4 \mathrm{~b}$ & Social Satisfaction & -.264 & -1.558 & -.231 & -1.026 & .351 & 2.052 & $221^{\circ}$ & $188^{\circ}$ & $215^{\circ}$ \\
\hline \multirow[t]{2}{*}{$\mathrm{H} 4 \mathrm{c}$} & Exit Barriers & -.139 & -1.195 & -.239 & -1.537 & .277 & 2.345 & $240^{\circ}$ & $222^{\circ}$ & $247^{\circ}$ \\
\hline & Resource Complementarity & -.042 & -.288 & -.057 & -.303 & .071 & .556 & $233^{\circ}$ & - & - \\
\hline \multirow[t]{5}{*}{ Controls } & Resource Complementarity & -.272 & -2.156 & .376 & 2.299 & .464 & 4.354 & $126^{\circ}$ & $74^{\circ}$ & $187^{\circ}$ \\
\hline & Competition between Partners & -.115 & -1.397 & .092 & .739 & .148 & 1.794 & $141^{\circ}$ & $141^{\circ}$ & $169^{\circ}$ \\
\hline & Age & -.036 & -.380 & -.024 & -.201 & .043 & .565 & $214^{\circ}$ & - & - \\
\hline & Gender & -.050 & -.588 & -.096 & -.788 & .109 & 1.249 & $242^{\circ}$ & - & - \\
\hline & Social Desirability & -.037 & -.442 & .006 & .053 & .038 & .534 & $171^{\circ}$ & - & - \\
\hline
\end{tabular}

${ }^{a}$ Angles represent the direction of the effect of the independent variable on the response strategy (that is, the consequence of a unit increase in an independent variable if the remaining independent variables are kept constant). The consequence of a unit decrease in an independent variable can be obtained by adding or subtracting $180^{\circ}$ from the angle.

${ }^{\mathrm{b}}$ Values in bold are significant at $5 \%$. 

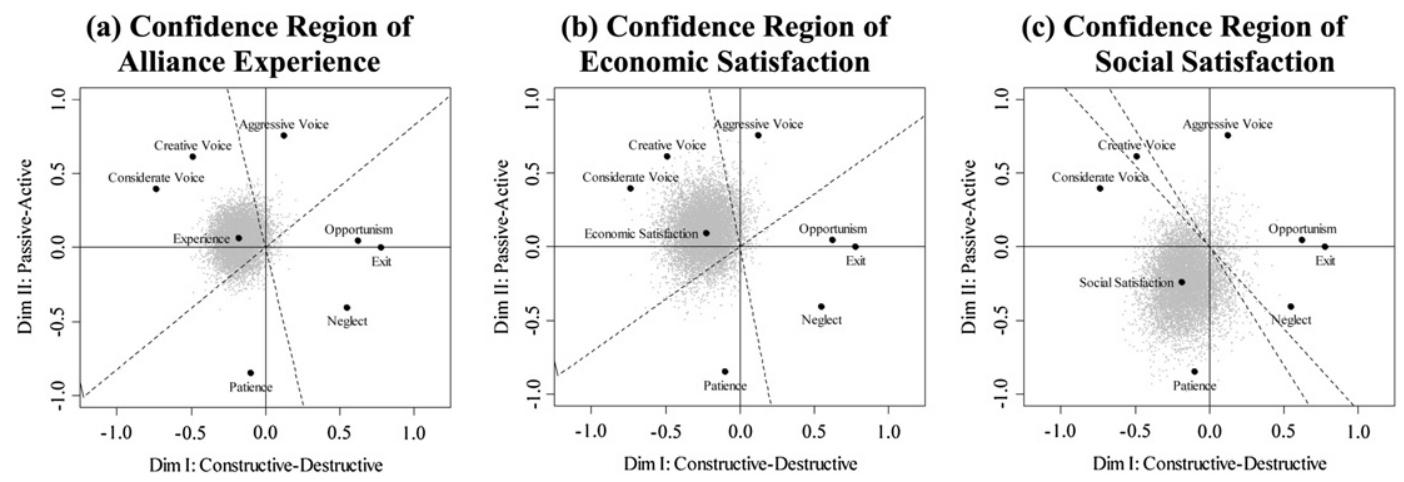

(d) Confidence Region of Exit Barriers

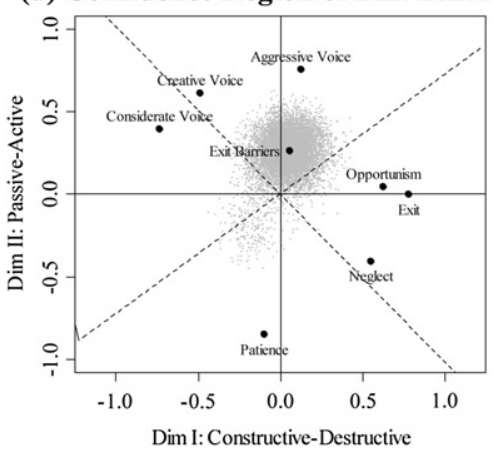

(e) Confidence Region of Competitive Pressure

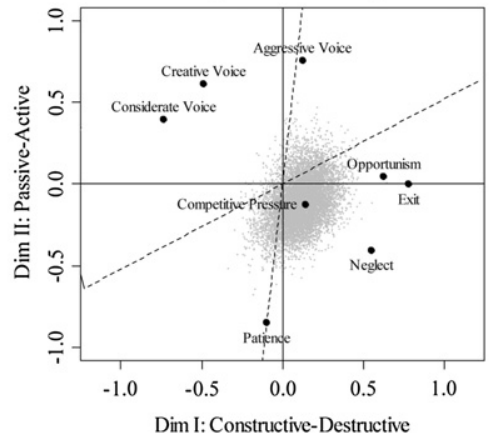

The grey dots represent bootstrap estimates (10,000 in each panel). The two dashed lines are the lines through the origin with the minimum/maximum angle so that the odds for a point to be on the one side of the line are $5 / 95$. These lines are exactly orthogonal to the minimum and maximum angle for which the effect of a predictor is significant (as reported in Table 3).

Figure 5. Bootstrap-based confidence regions

between $41^{\circ}$ and $128^{\circ}$ ) supports the notion that high exit barriers induce an active response. Low exit barriers have an effect on passive responses at an angle of $259^{\circ}\left(p<.05\right.$ between $221^{\circ}$ and $308^{\circ}$ ). This provides support for Hypothesis $2 \mathrm{c}$. Figure $5 \mathrm{~d}$ depicts the confidence region of exit barriers. Finally, the availability of alternatives does not influence any of the response strategy dimensions, and its radius is not significantly different from zero. So Hypothesis $2 \mathrm{~d}$ must be rejected.

The results provide mixed evidence for the role of environmental factors. The first factor, environmental turbulence, does not have a significant direct effect on a manager's response strategy. Hypothesis $3 \mathrm{a}$ is therefore rejected. Competitive pressure does have a significant effect. Although it does not influence any of the two identified response strategy dimensions in isolation, it shows a significant effect if the coordinate system is rotated between $13^{\circ}$ and $55^{\circ}$ clockwise toward more passive-destructive responses. Low competitive pressure induces active-constructive responses, between $193^{\circ}$ and $235^{\circ}$. Hypothesis $3 \mathrm{~b}$ is supported. Figure $5 \mathrm{a}$ visualizes the confidence region of the effect of competitive pressure.

We included the potential moderators, environmental turbulence and competitive pressure, sequentially into the structural model (see Table 3). This ensured a sensible ratio of observations per independent variable. Competitive pressure turned out not to have any moderating effect at all, rejecting Hypothesis 5. For reasons of parsimony, the study eliminated the non-significant interactions pertaining to competitive pressure from the analysis. While the results provide no support for the moderating effect of environmental turbulence and alliance experience, thus rejecting Hypothesis $4 \mathrm{a}$, the results do provide evidence for the strengthening effect of environmental turbulence on the relationship between economic satisfaction, social satisfaction and response strategy preference. This supports Hypothesis $4 \mathrm{~b}$. In addition, environmental turbulence weakens the effect 
of exit barriers on response strategies, but not the effect of available alternatives (eliminated from analysis). Thus, Hypothesis $4 \mathrm{c}$ is only partially supported.

Figure 6 graphically presents the model results, illustrating the single effects under the condition of environmental turbulence. In case of less environmental turbulence, high economic satisfaction is associated with a passive-constructive response and low economic satisfaction is associated with an active-destructive response, whereas environmental turbulence, economic satisfaction is associated with active (high) and passive (low) responses respectively. Social satisfaction has hardly any influence in less turbulent environments, but in highly turbulent environments high social satisfaction supports a passive-constructive response and low social satisfaction support an activedestructive response. The effect of exit barriers is limited to low environmental turbulence. Only then do high exit barriers stimulate active responses, whereas low exit barriers stimulate passive responses.

Several control variables have a significant influence on the response strategies. All alliance-level control variables are significant. Resource complementarity has a significant effect on the constructive-destructive dimension $(\beta=-.272, t=-2.156)$ and the passive-active dimension $(\beta=.376, t=2.299)$. The significant radius in combination with an angle of $126^{\circ}(p<.05$ between $74^{\circ}$ and $\left.187^{\circ}\right)$ supports the notion that high resource complementarity induces a constructiveactive response. Low resource complementarity, with an angle of $306^{\circ}$ ( $p<.05$ between $254^{\circ}$ and $7^{\circ}$ ), has an effect on passive-destructive responses. Competition between partners does not exhibit any significant effect on either of the two dimensions. However, effects between $141^{\circ}$ and $169^{\circ}$ are significant, which implies that high competition makes active-constructive responses $(p<.05$ between $254^{\circ}$ and $7^{\circ}$ ) more likely, whereas low competition induces active-destructive responses. The remaining individual control variables do not play any role. In line with Hair et al.'s (2012) recommendations for the treatment of insignificant predictor variables, the researchers kept all control variables in the model.

\section{Comparison of the explanatory power of the discrete and continuous models}

In order to assess the incremental explanatory power of the continuous model compared to the discrete model, we computed two reduced models. In the respective reduced models, to assess the consequence of Type-II error, only significant antecedents are maintained. Figure 4 illustrates the

(a) Model under Low Environmental Turbulence

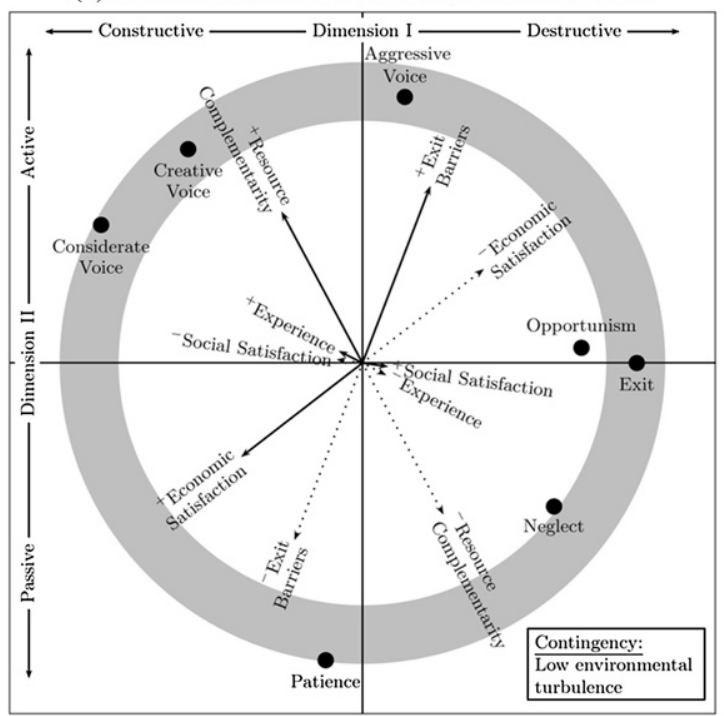

(b) Model under High Environmental Turbulence

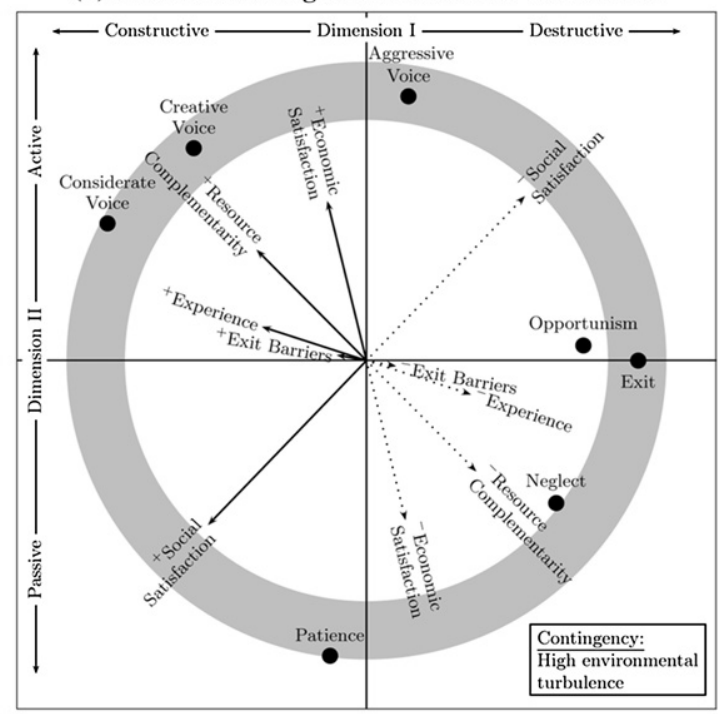

Figure 6. Moderating effects of environmental turbulence 
capabilities of the reduced discrete model and the reduced continuous model to explain the variation in the plane of response strategies. The area of the ellipse representing the explained variance of the continuous model is larger than the area of the ellipse representing the explained variance of the discrete model. In order to test whether the continuous model explains significantly more variance than the discrete model, we examined the difference in average adjusted $R^{2}$ between the two models. Bootstrapping with 5000 bootstrap samples revealed a significant difference $(p=.008)$ between the average adjusted $R^{2}$ of the circumplex model (.402) and the average adjusted $R^{2}$ of the discrete model (.285). This result indicates that taking into account the circumplex structure of response strategies reduces Type-II error.

\section{Discussion and conclusion}

The objective of this study was twofold: to extend and apply PLS path modeling to handle circumplex structures, and to develop and test a model of alliance partners' response strategies and key antecedents, accounting for the circumplex structure of response strategies.

We demonstrate that it is both possible and worthwhile to model circumplex constructs with PLS path modeling. Specifically, we show that by combining a hierarchical component structure with deflation, it becomes possible to extract two dimensions that span a plane of response strategies. Furthermore, we have enhanced PLS path modeling so that it can control the component rotation during its runtime. With this enhancement, our proposed method avoids inflation of the bootstrap standard errors by factor indeterminacy. We also can express the effects of potential antecedents in polar coordinates, which was necessary to specify the test of the antecedents on the circumplex structure and reduce Type-II error. We introduced a new form of bootstrapbased inference statistics when testing the effect of independent variables on a circumplex structure. By rotating the bootstrap path coefficients, we identified angles and significance regions for which a particular independent variable would have a significant effect in the plain of response strategies. In turn, we can obtain better specified tests and increased statistical power in the model. Overall, we demonstrate not only that PLS path modeling can be extended to assess circumplex structures but also that it is useful in strategy research. In many conditions associated with strategy studies (e.g., Swoboda et al., 2011) PLS is advantageous, including the relatively small sample size in relation to the model's complexity (i.e., number of variables and free parameters) and its focus on predicting strategy outcomes or firm behavior, rather than testing or comparing theories.

The survey results highlight the importance of accounting for the circumplex structure in assessing the effect of antecedents on response strategies. Had the analysis been limited to examining a discrete model (see the four leftmost columns of Table 3), the results would have rejected four of seven effects, similar to the findings of previous studies. Taking into account the circumplex structure by assessing the polar coordinates of the hypothesized effects allowed us to reject only two of seven hypothesized relationships (i.e., alternative availability and environmental turbulence). This step reduced Type-II error and increased the predictive power of the model. For example, when tested against the two dimensions, the effect of social satisfaction was not significant $(t=-1.447, p>.05)$ on the first constructivedestructive dimension, or on the second dimension $(t=-1.297, p>.05)$. However, after rotation, the effect of social satisfaction became significant at $5 \%$, between $188^{\circ}$ and $244^{\circ}$ (passive-constructive strategies) for high social satisfaction and between $8^{\circ}$ and $64^{\circ}$ (active-destructive strategies) for low social satisfaction. A comparison between the discrete model and the circumplex model in terms of explanatory power corroborates this observation: Taking into account the circumplex structure of response strategies when examining the effect of antecedents reduces Type-II error.

The results validate and extend prior response strategy research. Consistent with studies focusing on alliance-level factors, the results demonstrate that exchange conditions influence response strategy preference. In particular, as demonstrated by Geyskens and Steenkamp (2000), Ping (1999), and Tjemkes and Furrer (2010), the results indicate that economic and social satisfaction and exit barriers are significant predictors of response strategies. Contrary to findings by Hibbard et al. (2001), 
Ping (1993), and Tjemkes and Furrer (2010) though, we did not find any significant effect for available alternatives. This unexpected finding could be the result of a confounding effect with exit barriers; some studies (e.g., Ping, 1999), consider a lack of alternatives as an exit barrier. The findings also indicate that a manager's alliance experience and competitive pressure directly affect response strategy preference, whereas environmental turbulence moderates the effect of economic satisfaction, social satisfaction, and exit barriers. This study thereby extends prior work that has focused mainly on alliance factors (e.g., Hibbard et al., 2001; Ping, 1993; Tjemkes et al., 2012) by showing the relative importance of individual, alliance and environmental factors in explaining response strategy preferences.

We also extend prior response strategy research by demonstrating that variables discarded for their lack of significance become significant when they are tested against the circumplex structure of response strategies. This recognition could explain some of the unexpected results of prior response strategy studies. For example, Tjemkes and Furrer (2010) indicated that exit barriers did not significantly influence response strategy preferences, whereas our current findings indicate that exit barriers are associated with active responses. Furthermore, the model integrates prior response strategy research, which has focused on a limited number of discrete response strategies (e.g., Ping, 1997, 1999) or been limited to the empirical assessment of the circumplex structure without relating it to antecedents (Furrer et al., 2012). Thus, the study advances extant literature by presenting a response strategy model that provides a comprehensive answer to the question of which factors affect alliance partners' response behavior. In doing so, we also contribute to a better understanding of the complexity of managers' decision making in strategic alliances, in contrast with extant alliance research that has focused mostly on the consequences of such behavior (e.g., Ariño and de la Torre, 1998; Park and Ungson, 2001).

From a managerial standpoint, a model of response strategies is critical because it enables managers to allocate scarce resources efficiently in handling their alliances. Anticipating partners' behavior provides managers with early warning signals necessary to avoid a premature termination and provide firms with a competitive advantage (Ariño and Doz, 2000). Compared with models based on discrete response strategies, our model has two advantages. First, it shows that managers take into account the integrated structure of response strategies when making decisions rather than deciding on a response strategy in a piecemeal fashion. Second, the model incorporates a larger set of levers (i.e., individual, alliance and environmental factors) that managers can use to steer their alliance toward success and avoid premature termination. For example, managers should recognize that if their partner is acting opportunistically, its economic satisfaction is low and it has high exit barriers. Managers may then seek to increase partners' economic satisfaction to trigger constructive responses, or let them exit the alliance by reducing barriers. Thus, the model provides managers with deeper insights into an alliance partner's tendency to respond to distinct conditions and explicates the need to monitor changes in the predictors over time.

This study provides managers with two possible ways to anticipate an alliance partner's behavior. First, they can use the coefficients reported in Table 3. In combination with available levels of all significant predictor variables, these coefficients yield the $\mathrm{x}$ and $\mathrm{y}$ coordinates of a response. Response strategies closer to the predicted response strategy are more likely to be chosen (see Table 2 for the polar coordinates of the seven response strategies). Second, they might use Figure 5 to predict an alliance partner's behavior in a graphical way. Depending on the level of environmental turbulence, managers should use Figure $5 \mathrm{a}$ or $\mathrm{b}-$ or, an adequate interpolation of the two. The most likely response is obtained by concatenating the effects into one graph, and looking up the response strategy that is closest to the resulting point.

As does all research, our empirical study has certain limitations. First, we measured behavioral intentions, rather than actual behaviors, in an attempt to reduce recall and recency bias. Although intentions are not always perfect predictors of behavior, this approach uses behavioral intentions as early warning signals, so it seemed appropriate. When investigating actual behavior, it also could be 
useful to identify new interstitial response strategies, such as between patience and considerate voice, which might further improve the validity of the circumplex structure. In addition, research should investigate opportunism as a response strategy to disentangle how it deviates from the circumplex structure. A possible explanation might involve the presence of a third dimension, in which six response strategies are perceived as neutral in their moral content, but opportunism is not (Furrer et al., 2012).

Second, though the model includes three sets of factors, the inclusion of additional factors might enhance the model's explanatory power further. For example, additional research could incorporate technological change at the environmental level, coordination mechanisms at the alliance level (see Kashyap et al., 2012), and manager's risk propensity at the individual level (see Tjemkes and Furrer, 2011). In addition, studies might draw on attribution theory to examine the potential effect of attribution on response strategy preferences (Hibbard et al., 2001). Identifying the source of an adversity also may affect a manager's decision.

Third, in line with our hypotheses, we collected data by targeting a single respondent from one of the alliance partners. However, gathering data from both sides of a relationship and contacting multiple respondents within each partner firm would have enriched the study (Kumar et al., 1993). For example, including partner behavior (Bello et al., 2010; Hibbard et al., 2001) into the model likely would have increased its predictive power even further. Moreover, because strategic alliance decisions are often made by a team of managers, response strategies might more reliably be assessed using multiple respondents (Kumar et al., 1993).

Fourth, the cross-sectional nature of this study did not make it possible to assess time lags between response strategies. Building on work by Doz (1996) and Ariño and de la Torre (1998), further research should design more sophisticated longitudinal studies to examine changes in response strategies over time.

Fifth and finally, we tested the model in the context of SMEs and focused on non-equity alliances. Additional studies should test the model in the context of large firms and examine equity-based alliances to enable the generalization of these findings across contexts.

This study extended PLS path modeling and tested a model of response strategies. The results of the empirical part of the study demonstrate the relevance of conceptualizing the structure of these response strategies as a circumplex. A key implication of modeling response strategies as part of an integrated set of factors is that it provides a means to predict responses, anticipate partner behavior, and manage alliances toward success. Consequently, the present study provides valuable guidelines for managers who are confronted with a need to respond to alliance adversities.

\section{Appendix A. Operationalization of study constructs (Adapted from Tjemkes and Furrer, 2010)}

\begin{tabular}{|c|c|c|c|}
\hline $\begin{array}{l}\text { Response } \\
\text { Strategies }\end{array}$ & Description & Item & $\begin{array}{l}\text { Standardized } \\
\text { Loading }\end{array}$ \\
\hline Exit & $\begin{array}{l}\text { The disinclination to continue } \\
\text { the current relationship } \\
\text { (Ping, 1993; } \\
\text { Rusbult et al., 1982) }\end{array}$ & $\begin{array}{l}\text { Ex1: I will consider ending the } \\
\text { alliance with my partner. } \\
\text { Ex2: I think I will probably stop } \\
\text { doing business with my partner. } \\
\text { Ex3: I am not likely to continue } \\
\text { the alliance with my partner. } \\
\text { Ex4: I intend to exit the alliance. }\left(^{a}\right) \\
\text { Ex5: I believe I will terminate } \\
\text { the alliance. }\end{array}$ & $\begin{array}{l}.859 \\
- \\
.944\end{array}$ \\
\hline
\end{tabular}


Appendix A. (continued)

\begin{tabular}{|c|c|c|c|}
\hline $\begin{array}{l}\text { Response } \\
\text { Strategies }\end{array}$ & Description & Item & $\begin{array}{l}\text { Standardized } \\
\text { Loading }\end{array}$ \\
\hline \multirow[t]{6}{*}{ Opportunism } & \multirow{6}{*}{$\begin{array}{l}\text { Self-interested behavior } \\
\text { that is explicitly or } \\
\text { implicitly prohibited } \\
\text { (Ping, 1993; Wathne } \\
\text { and Heide, 2000). }\end{array}$} & $\begin{array}{l}\text { Op1: I will purposefully exaggerate } \\
\text { the situation in order to receive } \\
\text { additional benefits. }\end{array}$ & .791 \\
\hline & & $\begin{array}{l}\text { Op2: I will change the facts slightly } \\
\text { in order to get what I need from } \\
\text { my partner. }\end{array}$ & .738 \\
\hline & & $\begin{array}{l}\text { Op3: I will deliberately make the } \\
\text { situation sound more problematic } \\
\text { than it really is to obtain more } \\
\text { benefits from the alliance. }\end{array}$ & .779 \\
\hline & & $\begin{array}{l}\text { Op4: In order to improve the } \\
\text { situation, I will try to avoid } \\
\text { certain contractual obligations. }\end{array}$ & .628 \\
\hline & & $\begin{array}{l}\text { Op5: I will withhold important } \\
\text { information from my partner } \\
\text { to gain additional benefits. }\end{array}$ & .733 \\
\hline & & $\begin{array}{l}\text { Op6: I will describe the situation } \\
\text { as negatively as possible to my } \\
\text { partner in order to gain } \\
\text { additional benefits. }\end{array}$ & .846 \\
\hline \multirow[t]{5}{*}{ Aggressive voice } & \multirow{5}{*}{$\begin{array}{l}\text { A form of voice that consists } \\
\text { of efforts to win without } \\
\text { consideration for the concerns } \\
\text { of the exchange partner } \\
\text { (Hagedoorn et al., 1999). }\end{array}$} & $\begin{array}{l}\text { Agr1: I will forcefully push my } \\
\text { firm's solution to improve } \\
\text { the situation. }\left({ }^{a}\right)\end{array}$ & - \\
\hline & & $\begin{array}{l}\text { Agr2: I will use my power to solve } \\
\text { situation in a way that suits my firm. }\end{array}$ & .690 \\
\hline & & $\begin{array}{l}\text { Agr3: I will prove in all possible } \\
\text { ways to my partner that my firm's } \\
\text { solution for the situation is right. }\end{array}$ & .747 \\
\hline & & $\begin{array}{l}\text { Agr4: I will be very persistent with } \\
\text { my partner to have them accept my } \\
\text { firm's solution to the situation. }\end{array}$ & .748 \\
\hline & & $\begin{array}{l}\text { Agr5: I will strongly advocate my } \\
\text { firm's solution to solve the situation } \\
\text { with the alliance. }\end{array}$ & .829 \\
\hline \multirow[t]{6}{*}{ Creative voice } & \multirow{6}{*}{$\begin{array}{l}\text { A form of voice that consists } \\
\text { of the generation of novel } \\
\text { and potentially useful ideas } \\
\text { (Zhou and George, 2001). }\end{array}$} & $\begin{array}{l}\text { Crel: I will adopt a fresh approach } \\
\text { to improve the situation. }\end{array}$ & .739 \\
\hline & & $\begin{array}{l}\text { Cre2: I will come up with new ideas } \\
\text { to improve the situation with the } \\
\text { alliance. }\left({ }^{\mathrm{a}}\right)\end{array}$ & - \\
\hline & & $\begin{array}{l}\text { Cre3: I will suggest constructive } \\
\text { changes to my partner to improve } \\
\text { the situation. }\end{array}$ & .640 \\
\hline & & $\begin{array}{l}\text { Cre4: I will search for new and } \\
\text { innovative ideas to improve } \\
\text { the situation. }\end{array}$ & .736 \\
\hline & & $\begin{array}{l}\text { Cre5: I will propose creative solutions } \\
\text { to my partner to improve the situation. }\end{array}$ & .842 \\
\hline & & $\begin{array}{l}\text { Cre6: I will suggest new creative ways } \\
\text { to improve the situation. }\end{array}$ & .816 \\
\hline
\end{tabular}


Appendix A. (continued)

\begin{tabular}{|c|c|c|c|}
\hline $\begin{array}{l}\text { Response } \\
\text { Strategies }\end{array}$ & Description & Item & $\begin{array}{l}\text { Standardized } \\
\text { Loading }\end{array}$ \\
\hline \multirow[t]{6}{*}{ Considerate voice } & \multirow{6}{*}{$\begin{array}{l}\text { A form of voice that consists } \\
\text { of attempts to solve the } \\
\text { situation by considering one's } \\
\text { own concerns as well as those } \\
\text { of the partner (Ping, 1993). }\end{array}$} & $\begin{array}{l}\text { Con1: I will try to reaching an } \\
\text { understanding with my partner to } \\
\text { solve the situation. }\end{array}$ & .846 \\
\hline & & $\begin{array}{l}\text { Con2: I will work to create a consensus } \\
\text { with my partner to solve the situation. }\end{array}$ & .796 \\
\hline & & $\begin{array}{l}\text { Con3: I will approach my partner with } \\
\text { a proposition to solve the situation } \\
\text { and work it out together. }\left({ }^{\mathrm{a}}\right)\end{array}$ & - \\
\hline & & $\begin{array}{l}\text { Con4: In collaboration with my partner, } \\
\text { I will try to find a solution that is } \\
\text { satisfactory to everyone. }\end{array}$ & .700 \\
\hline & & $\begin{array}{l}\text { Con5: I will contact my partner to find } \\
\text { an acceptable solution for both partners. }\end{array}$ & .847 \\
\hline & & $\begin{array}{l}\text { Con6: I will talk to my partner to find } \\
\text { a mutual satisfactory solution to } \\
\text { improve the situation. }\end{array}$ & .900 \\
\hline \multirow[t]{6}{*}{ Patience } & \multirow{6}{*}{$\begin{array}{l}\text { Abiding relationship issues in } \\
\text { silence with the confidence } \\
\text { that things will get better } \\
\text { (Hagedoorn et al., 1999; } \\
\text { Ping, 1993) }\end{array}$} & Pat1: I trust the situation will solve itself. & .835 \\
\hline & & $\begin{array}{l}\text { Pat2: I will not say anything to my } \\
\text { partner because I expect the situation } \\
\text { to go away by itself. }\end{array}$ & .711 \\
\hline & & $\begin{array}{l}\text { Pat3: I will wait optimistically for } \\
\text { better times. }\end{array}$ & .746 \\
\hline & & $\begin{array}{l}\text { Pat4: I will wait patiently and hope the } \\
\text { situation solves itself. }\end{array}$ & .662 \\
\hline & & $\begin{array}{l}\text { Pat5: I expect that soon everything will } \\
\text { work out with the alliance. }\end{array}$ & .780 \\
\hline & & $\begin{array}{l}\text { Pat6: I am confident that in the end the } \\
\text { situation will be resolved. }\end{array}$ & .772 \\
\hline \multirow[t]{6}{*}{ Neglect } & \multirow{6}{*}{$\begin{array}{l}\text { Passively allowing the } \\
\text { relationship to deteriorate } \\
\text { (Ping, 1993; Rusbult et al., } \\
\text { 1982) }\end{array}$} & $\begin{array}{l}\text { Neg1: I do not plan anything extra to } \\
\text { solve the situation with the alliance. }\left({ }^{a}\right)\end{array}$ & - \\
\hline & & $\begin{array}{l}\text { Neg2: I will not initiate anything to } \\
\text { improve the situation with the } \\
\text { alliance. }\left({ }^{a}\right)\end{array}$ & - \\
\hline & & $\begin{array}{l}\text { Neg3: I will passively let the alliance } \\
\text { with my partner end. }\end{array}$ & .594 \\
\hline & & $\begin{array}{l}\text { Neg4: I will not deal with the situation } \\
\text { with the alliance. }\end{array}$ & 693 \\
\hline & & $\begin{array}{l}\text { Neg5: I do not intend to invest anymore } \\
\text { in the alliance with my partner to } \\
\text { solve the situation. }\end{array}$ & .728 \\
\hline & & $\begin{array}{l}\text { Neg6: I do not intent to put any effort } \\
\text { into the alliance to improve the situation }\end{array}$ & .804 \\
\hline
\end{tabular}

\footnotetext{
${ }^{\mathrm{a}}$ Excluded from data analysis.
} 


\section{Appendix B. Hierarchical component model of response strategies}

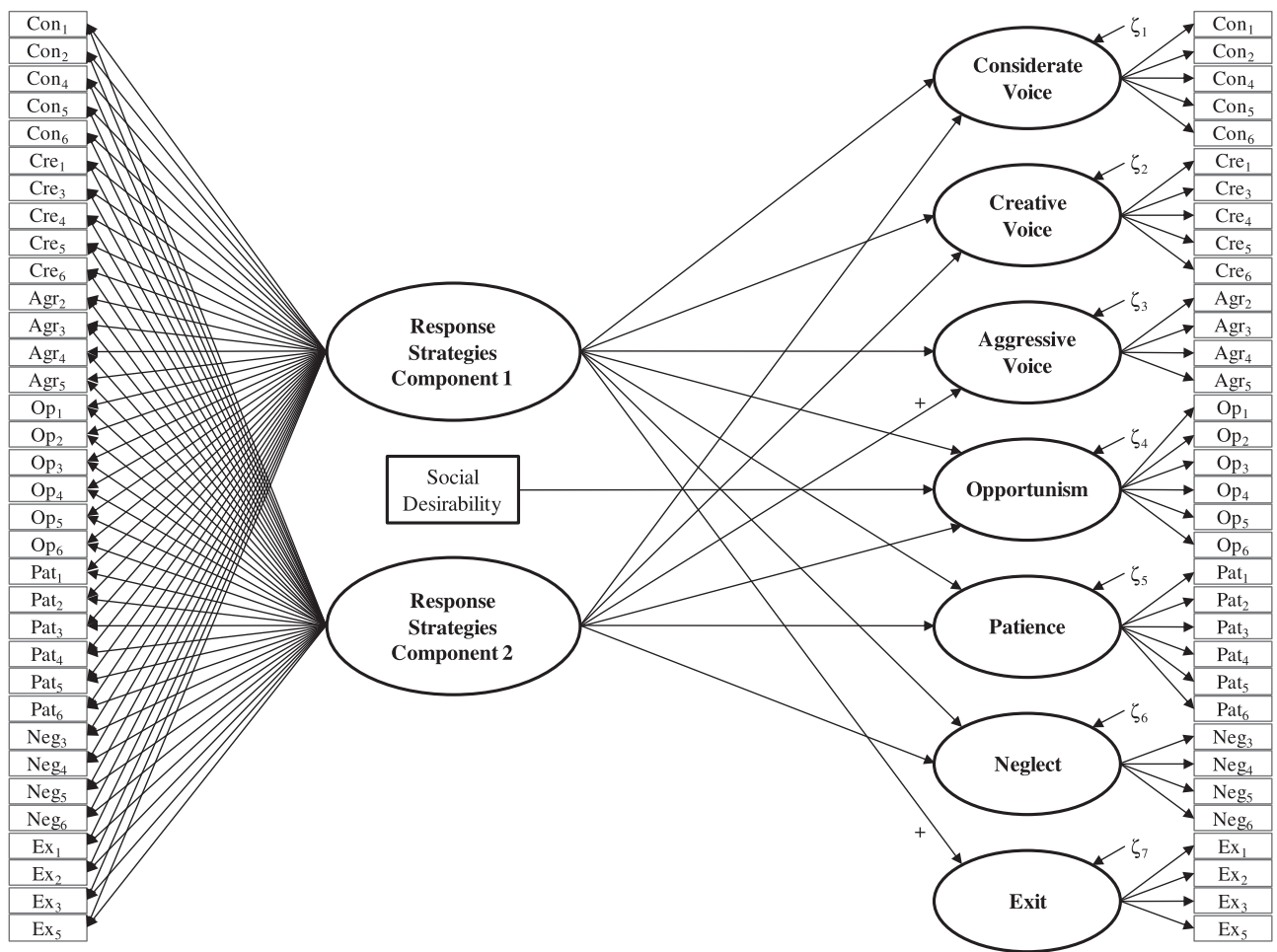

\section{Appendix C. Covariance-based circumplex models}

The table below provides a model comparison based on the results of maximum-likelihood covariance-based structural equation modeling (as implemented in AMOS 19). The model is estimated relying on the latent variable scores as obtained through PLS path modeling. We estimated three models with regard to the dimensionality of the seven response strategies (see Perrinjaquet et al., 2007). Model 1 postulates a discrete two-dimensional structure of the seven response strategies. Model 2 postulates a continuous circumplex structure, which means that two factors can explain the seven response strategies such that the $R^{2}$ values of all response strategies are equal. Model 3 postulates a circumplex model in which the equality constraint was released for the radius of opportunism. Model 2 is nested in Model 3, and Model 3 is nested in Model 1. Since the latent variable scores cannot assumed to be normal distributed (Goodhue et al., 2006), we use the Bollen-Stine bootstrap (Bollen and Stine, 1992) as test of exact fit. The results show that Model 2 poorly fits the data, Model 1 has the highest absolute fit, and Model 3 excels with regard to parsimony-adjusted fit. As Model 3 is more parsimonious, these results support a circumplex structure confirming PLS results. 


\begin{tabular}{|c|c|c|c|}
\hline Model & Model 1 & Model 2 & Model 3 \\
\hline \multicolumn{4}{|l|}{ Structure } \\
\hline Dimensionality & $\begin{array}{l}\text { Discrete } \\
\text { two-dimensional }\end{array}$ & Circumplex 1 & Circumplex 2 \\
\hline Degrees of freedom & 123.000 & 117.000 & 118.000 \\
\hline Minimum discrepancy $\left(\mathrm{F}_{\min }\right)$ & 1.087 & 1.342 & 1.240 \\
\hline $\begin{array}{l}\text { Bollen-Stine bootstrap p-value } \\
\text { (with } 1000 \text { resamples) }\end{array}$ & .108 & .044 & .077 \\
\hline Goodness of fit index (GFI) & .901 & .881 & .890 \\
\hline $\begin{array}{l}\text { Parsimony-adjusted goodness } \\
\text { of fit index (PGFI) }\end{array}$ & .318 & .338 & .337 \\
\hline Comparative fit index (CFI) & .910 & .870 & .888 \\
\hline $\begin{array}{l}\text { Parsimony-adjusted comparative } \\
\text { fit index (PCFI) }\end{array}$ & .356 & .371 & .374 \\
\hline Akaike information criterion (AIC) & 360.162 & 374.953 & 366.154 \\
\hline Browne-Cudeck criterion (BCC) & 418.044 & 430.012 & 421.684 \\
\hline Bayes information criterion (BIC) & 687.765 & 686.575 & 680.440 \\
\hline Consistent AIC (CAIC) & 810.765 & 803.575 & 798.440 \\
\hline $\begin{array}{l}\text { Standardized root mean square } \\
\text { residual (SRMR) }\end{array}$ & .053 & .052 & .051 \\
\hline
\end{tabular}

\section{References}

Aldrich, H., 1979. Organizations and Environments. Prentice-Hall, Englewood Cliffs, N.J.

Anderson, J.C., Gerbing, D.W., 1988. Structural equation modeling in practice: a review and recommended two-step approach. Psychological Bulletin 103, 411-423.

Ariño, A., de la Torre, J., 1998. Learning from failure: towards an evolutionary model of collaborative ventures. Organization Science 9, 306-325.

Ariño, A., Doz, Y., 2000. Rescuing troubled alliances. Before it's too late. European Management Journal 18, $173-182$.

Axelrod, R., 1986. An evolutionary approach to norms. American Political Science Review 80, 1095-1111.

Bello, D.C., Katsikeas, C.S., Robson, M.J., 2010. Does accommodating a self-serving partner in an international marketing alliance pay off? Journal of Marketing 74, 77-93.

Bollen, K.A., Stine, R.A., 1992. Bootstrapping goodness-of-fit measures in structural equation models. Sociological Methods Research 21, 205-229.

Brock, J.K.-U., 2003. The 'power' of international business research. Journal of International Business Studies $34,90-99$.

Brouthers, K.D., Bamossy, G.J., 2006. Post-formation processes in Eastern and Western European joint ventures. Journal of Management Studies 43, 203-229.

Calantone, R., García, R., Dröge, C., 2003. The effects of environmental turbulence on new product development strategy planning. Journal of Product Innovation Management 20 (2), 90-103.

Cassel, C., Hackl, P., Westlund, A.H., 1999. Robustness of partial least-squares method for estimating latent variable quality structures. Journal of Applied Statistics 26, 435-446.

Chin, W.W., Newsted, P.R., 1999. Structural equation modeling analysis with small samples using partial least squares. In: Hoyle, R.H. (Ed.), Statistical Strategies for Small Sample Research. Sage, Thousand Oaks, pp. 307-342. 
Cronbach, L.J., 1987. Statistical tests for moderator variables: flaws in analyses recently proposed. Psychological Bulletin 102 (3), 414-417.

Daft, R.L., Sormunen, J., Parks, D., 1988. Chief executive scanning, environmental characteristics, and company performance: an empirical study. Strategic Management Journal 9, 123-140.

Das, T.K., Teng, B.-S., 2000. A resource-based theory of strategic alliances. Journal of Management 26, 31-61.

Deeds, D.L., Hill, C.W.L., 1998. An examination of opportunistic action within research alliances: evidence from the biotechnology industry. Journal of Business Venturing 14, 141-163.

Deutskens, E., de Ruyter, K., Wetzels, M., Oosterveld, P., 2004. Response rate and response quality of internetbased surveys: an experimental study. Marketing Letters 15, 21-36.

Doz, Y.L., 1996. The evolution of cooperation in strategic alliances: initial conditions or learning processes? Strategic Management Journal 17, 55-83.

Dutton, J.E., Jackson, E.E., 1987. Categorizing strategic issues: links to organizational action. Academy of Management Review 12, 76-90.

Fabrigar, L.R., Visser, P.S., Browne, M.W., 1997. Conceptual and methodological issues in testing the circumplex structure of data in personality and social psychology. Personality and Social Psychology Review 1, 184-203.

Farrell, D., 1983. Exit, voice, loyalty, and neglect as responses to job dissatisfaction: a multidimensional scaling study. Academy of Management Journal 26, 596-607.

Fornell, C., Larcker, D.F., 1981. Evaluating structural equation models with unobservable variables and measurement error. Journal of Marketing Research 18 (1), 39-50.

Furrer, O., Thomas, H., 2000. The rivalry matrix: understanding rivalry and competitive dynamics. European Management Journal 18, 619-637.

Furrer, O., Tjemkes, B.V., Ulgen Aydinlik, A., Adolfs, K., 2012. Responding to adverse situations within exchange relationships: the cross-cultural validity of a circumplex model. Journal of Cross-Cultural Psychology 43, 934-966.

Fynes, B., de Búrca, S., Marshall, D., 2004. Environmental uncertainty, supply chain relationship quality and performance. Journal of Purchasing and Supply Management 10, 179-190.

Gefen, D., Rigdon, E.E., Straub, D., 2011. An update and extension to SEM guidelines for administrative and social science research. MIS Quarterly 35, iii-xiv.

Geyskens, I., Steenkamp, J.-B.E.M., 2000. Economic and social satisfaction: measurement and relevance to marketing channel relationships. Journal of Retailing 76, 11-32.

Goodhue, D., Lewis, W., Thompson, R., 2006. PLS, small sample size, and statistical power in: MIS research. In: Sprague, R. (Ed.), Proceedings of the 39th Annual Hawaii International Conference on System Sciences. IEEE Computer Society Press, Los Alamitos, CA, pp. 1-10.

Goodhue, D., Lewis, W., Thompson, R., 2007. Statistical power in analyzing interaction effects: questioning the advantage of PLS with product indicators. Information Systems Research 18 (2), 211-227.

Hagedoorn, M., Yperen, N.W., Van de Vliert, E., Buunk, B.P., 1999. Employees' reactions to problematic events: a circumplex structure of five categories of responses, and the role of job satisfaction. Journal of Organizational Behavior 20, 309-321.

Hair, J.F., Sarstedt, M., Ringle, C.M., Mena, J.A., 2012. An assessment of the use of partial least squares structural equation modeling in marketing research. Journal of the Academy of Marketing Science 40 (3), 414-433.

Hambrick, D.C., Mason, P.A., 1984. Upper echelons: the organization as a reflection of its top executives. Academy of Management Review 9, 193-206.

Hennart, J.F., 2006. Alliance research: less is more. Journal of Management Studies 43, 1621-1628.

Henseler, J., 2010. On the convergence of the partial least squares path modeling algorithm. Computational Statistics 25, 107-120.

Henseler, J., Chin, W.W., 2010. A comparison of approaches for the analysis of interaction effects between latent variables using partial least squares path modeling. Structural Equation Modeling 17, 82-109.

Henseler, J., Fassott, G., Dijkstra, T.K., Wilson, B., 2012. Analysing quadratic effects of formative constructs by means of variance-based structural equation modeling. European Journal of Information Systems 21 (1), 99-112.

Henseler, J., Ringle, C.M., Sinkovics, R.R., 2009. The use of partial least squares path modeling in international marketing. Advances in International Marketing 20, 277-319.

Henseler, J., Sarstedt, M., 2012. Goodness-of-fit indices for partial least squares path modeling. Computational Statistics. http://dx.doi.org/10.1007/s00180-012-0317-1. 
Hibbard, J.D., Kumar, N., Stern, L.W., 2001. Examining the impact of destructive acts in marketing channel relationships. Journal of Marketing Research 38, 45-61.

Hirschman, A.O., 1970. Exit, Voice and Loyalty: Responses to Decline in Firms, Organizations and States. Harvard University Press, Cambridge, MA.

Hoang, H., Rothaermel, F.T., 2005. The effect of general and partner-specific alliance experience on joint R\&D project performance. Academy of Management Journal 48, 332-345.

Hughes, J., Weiss, J., 2007. Simple rules for making alliances work. Harvard Business Review 85 (11), $122-131$.

Kale, P., Singh, H., 2009. Managing strategic alliances: what do we know now, and where do we go from here? Academy of Management Perspectives 23, 45-62.

Kandemir, D., Yaprak, A., Cavusgil, S.T., 2006. Alliance orientation: conceptualization, measurement, and impact on market performance. Journal of the Academy of Marketing Science 34, 324-340.

Kashyap, V., Antia, K.D., Frazier, G.L., 2012. Contracts, extracontractual incentives, and ex post behavior in franchise channel relationships. Journal of Marketing Research 49, 260-276.

Kumar, N., Stern, L.W., Anderson, J.C., 1993. Conducting interorganizational research using key informants. Academy of Management Journal 36 (6), 1633-1651.

Kumar, R., Nti, K.O., 2004. National cultural values and the evolution of process and outcome discrepancies in international strategic alliances. Journal of Applied Behavioral Science 40 (3), 344-361.

Lambe, C.J., Spekman, R.E., Hunt, S.D., 2002. Alliance competence, resources, and alliance success: conceptualization, measurement, and initial test. Journal of the Academy of Marketing Science 30, 141-158.

Lance, C.E., 1988. Residual centering, exploratory and confirmatory moderator analysis, and decomposition of effects in path models containing interactions. Applied Psychological Measurement 12 (2), 163-175.

Lohmöller, J.-B., 1989. Latent Variable Path Modeling with Partial Least Squares. Physica, Heidelberg.

Mintzberg, H., 1973. The Nature of Managerial Work. Harper \& Row, New York.

Nunnally, J.C., 1978. Psychometric Theory, second ed. McGraw-Hill, New York.

Obenchain, R.L., 1999. Resampling and multiplicity in cost-effectiveness inference. Journal of Biopharmaceutical Statistics 9 (4), 563-582.

Olk, P., Young, C., 1997. Why members stay in or leave an R\&D consortium: performance and conditions of membership as determinants of continuity. Strategic Management Journal 18, 855-877.

Pansiri, J., 2005. The influence of managers' characteristics and perceptions in strategic alliance practice. Management Decision 43 (9), 1097-1113.

Parise, S., Sasson, L., 2002. Leveraging knowledge management across strategic alliances. Ivey Business Journal March/April, 41-47.

Park, S.H., Ungson, G.R., 2001. Interfirm rivalry and managerial complexity: a conceptual framework of alliance failure. Organization Science 12, 37-53.

Paulraj, A., Chen, J.C., 2007. Environmental uncertainty and strategic supply management: a resource dependence perspective and performance implications. Journal of Supply Chain Management 43 (3), 29-42.

Pekar, P., Allio, R., 1994. Making alliances work: guidelines for Success. Long Range Planning 27 (4), 54-65.

Perrinjaquet, A., Furrer, O., Usunier, J.-C., Cestre, G., Valette-Florence, P., 2007. A test of the quasicircumplex structure of human values. Journal of Research in Personality 41, 820-840.

Ping, R.A., 1993. The effects of satisfaction and structural constraints on retailer exiting, voice, loyalty, opportunism, and neglect. Journal of Retailing 69, 320-352.

Ping, R.A., 1997. Voice in business-to-business relationships: cost-of-exit and demographic antecedents. Journal of Retailing 73, 261-281.

Ping, R.A., 1999. Unexplored antecedents of exiting in a marketing channel. Journal of Retailing 75, 218-241.

Porter, M.E., 1980. Competitive Strategy. Free Press, New York.

R Development Core Team, 2011. R: A Language and Environment for Statistical Computing. R Foundation for Statistical Computing, Vienna, Austria. http://www.R-project.org/.

Reinartz, W.J., Haenlein, M., Henseler, J., 2009. An empirical comparison of the efficacy of covariance-based and variance-based SEM. International Journal of Market Research 26, 332-344.

Ringle, C.M., Sarstedt, M., Straub, D.W., 2012. A critical look at the use of PLS-SEM in MIS Quarterly. MIS Quarterly 36, iii-xiv.

Ringle, C., Wende, S., Will, A., 2005. SmartPLS 2.0 (Beta) Hamburg. www.smartpls.de.

Rusbult, C.E., Farrell, D., 1983. A longitudinal test of the investment model: the impact on job-satisfaction, job commitment, and turnover of variations in rewards, costs, alternatives, and investments. Journal of Applied Psychology 68, 429-438. 
Rusbult, C.E., Farrell, D., Rogers, G., Mainous, A.G., 1988. Impact of exchange variables on exit, voice, loyalty, and neglect: an integrative model of responses to declining job satisfaction. Academy of Management Journal 31, 599-627.

Rusbult, C.E., Zembrodt, I.M., Gunn, L.K., 1982. Exit, voice, loyalty, and neglect: responses to dissatisfaction in romantic involvements. Journal of Personality and Social Psychology 43, 1230-1242.

Scherer, F.M., Ross, D., 1990. Industrial Market Structure and Economic Performance, third ed. HoughtonMifflin, Boston.

Schwartz, S., 2012. Toward refining the theory of basic human values. In: Salzborn, S., Davidov, E., Reinecke, J. (Eds.), Methods, Theories, and Empirical Applications in the Social Sciences. Springer, Wiesbaden, pp. 39-46.

Slater, S.F., Narver, J.C., 1994. Does competitive environment moderate the market orientation-performance relationship. Journal of Marketing 58 (1), 46-55.

Strahan, R., Gerbasi, K.C., 1972. Short, homogeneous versions of Marlow-Crowne social desirability scale. Journal of Clinical Psychology 28, 191-193.

Swoboda, B., Meierer, M., Foscht, T., Morschett, D., 2011. International SME alliances: the impact of alliance building and configurational fit on success. Long Range Planning 44, 271-288.

Tjemkes, B., Furrer, O., 2010. The antecedents of response strategies in strategic alliances. Management Decision 48, 1103-1133.

Tjemkes, B., Furrer, O., 2011. Behavioral responses to adverse situations in strategic alliances. In: Das, T.K. (Ed.), Behavioral Perspectives on Strategic Alliances, Research in Strategic Alliance Book Series. Information Age Publishing, Charlotte, pp. 227-249 (Chapter 10).

Tjemkes, B.V., Furrer, O., Adolfs, K., Ulgen Aydinlik, A., 2012. Response strategies in an international strategic alliance experimental context: cross-country differences. Journal of International Management 18, 66-84.

Wathne, K.H., Heide, J.B., 2000. Opportunism in interfirm relationships: forms, outcomes, and solutions. Journal of Marketing 64, 36-51.

Wetzels, M., Oderkerken-Schröder, G., van Oppen, C., 2009. Using PLS path modeling for assessing hierarchical construct models: guidelines and empirical illustration. MIS Quarterly 33, 177-195.

Wold, H.O.A., 1982. Soft Modeling: the basic design and some extensions. In: Wold, H.O.A., Jöreskog, K.G. (Eds.), 1982. Systems under Indirect Observation. Causality, Structure, Prediction, vol. II. North-Holland, Amsterdam, pp. 1-54.

Zhou, J., George, J.M., 2001. When job dissatisfaction leads to creativity: encouraging the expression of voice. Academy of Management Journal 44, 682-697.

\section{Biographies}

Dr. Olivier Furrer is Associate Professor of Strategic Management at the Nijmegen School of Management of the Radboud University, Nijmegen (NL). His work has been published in the Journal of International Business Studies, Journal of International Management and Management International Review, among others. Furrer's current research interests are international corporate social responsibilities and response strategies in strategic alliances. E-mail: o.furrer@fm.ru.nl

Dr. Brian V. Tjemkes is Associate Professor in the Department of Management and Organization in the Faculty of Economics and Business Administration at VU University, Amsterdam (NL). Tjemkes' work has been published in such journals as the Journal of Cross-Cultural Psychology, Journal of International Management, Journal of Management Studies and Management Decision. His research interests include the management and performance of strategic alliances. E-mail: b.v.tjemkes@vu.nl

Dr. Jörg Henseler is Associate Professor of Marketing at the Institute for Management Research, Radboud University, Nijmegen (NL), and a visiting professor at New University of Lisbon (PT). He has published in Structural Equation Modeling, Computational Statistics, and Management Decision, among others, and is an editor of the Handbook of Partial Least Squares (Springer 2010). His research interests include PLS and managing inter-firm relationships. E-mail: j.henseler@fm.ru.nl 